\title{
P2X-GCaMPs as Versatile Tools for Imaging Extracellular ATP Signaling
}

\author{
Matthias Ollivier, ${ }^{1,3}$ Juline Beudez, ${ }^{2}$ Nathalie Linck, ${ }^{1,3}$ Thomas Grutter, ${ }^{2}$ Vincent Compan, ${ }^{1,3,{ }^{*}}$ and \\ (-)Francois Rassendren ${ }^{1,3, *}$
}

\section{https://doi.org/10.1523/ENEURO.0185-20.2020}

${ }^{1}$ Institut de Génomique Fonctionnelle, Université de Montpellier, Centre National de la Recherche Scientifique, Institut National de la Santé et de la Recherche Médicale, Montpellier, France, ${ }^{2}$ Centre National de la Recherche Scientifique, Laboratoire de Conception et Application de Molécules Bioactives Unité Mixte de Recherche 7199, Équipe de Chimie et Neurobiologie Moléculaire, Université de Strasbourg, Strasbourg, France, and ${ }^{3}$ LabEx Ion Channel Science and Therapeutics, Montpellier, France

\begin{abstract}
ATP is an extracellular signaling molecule involved in numerous physiological and pathologic processes. However, in situ characterization of the spatiotemporal dynamic of extracellular ATP is still challenging because of the lack of sensor with appropriate specificity, sensitivity, and kinetics. Here, we report the development of biosensors based on the fusion of cation permeable ATP receptors (P2X) to genetically encoded calcium sensors [genetically encoded calcium indicator (GECI)]. By combining the features of P2X receptors with the high signal-to-noise ratio of GECls, we generated ultrasensitive green and red fluorescent sniffers that detect nanomolar ATP concentrations in situ and also enable the tracking of P2X receptor activity. We provide the proof of concept that these sensors can dynamically track ATP release evoked by depolarization in mouse neurons or by extracellular hypotonicity. Targeting these P2X-based biosensors to diverse cell types should advance our knowledge of extracellular ATP dynamics in vivo.
\end{abstract}

Key words: ATP; biosensor; GECl; P2X; purinergic signaling

\section{Significance Statement}

Purinergic signaling plays an important role in regulating neuro-glial communications and, as a consequence, in the modulation of network activities. Current ATP biosensors lack appropriate sensitivity and kinetics to precisely decipher the spatiotemporal dynamic of extracellular ATP in situ. We developed a series of ATP biosensors based on the fusion of calcium-permeant P2X receptors to the calcium indicator GCaMP6s. These sensors display fast kinetics and sensitivity allowing to dynamically detect sub-micromolar ATP concentration. We provide direct evidence that these sensors can dynamically detect ATP release evoked by $\mathrm{KCl}$ depolarization in neurons, or by osmotic-evoked cell swelling. These sensors can also be adapted in red-shifted versions, offering a toolbox to assess purinergic signaling in situ.

\section{Introduction}

ATP is a ubiquitous molecule that provides cellular energy to all living organisms. In most species, except in insects and nematodes (Hou and Cao, 2016), ATP is also an extracellular messenger that allows cell-to-cell signaling through activation of specific purinergic plasma membrane

\footnotetext{
Received May 9, 2020; accepted December 7, 2020; First published December 30, 2020.

The authors declare no competing financial interests.
}

receptors (Burnstock, 2018). ATP signaling is involved in the regulation of plethora of physiological functions and increasing number of evidence supports that purinergic signaling components are remodeled in pathologic conditions, thereby directly contributing to diseases manifestation (Burnstock, 2006). and F.R. analyzed data; M.O., T.G., V.C., and F.R. wrote the paper. 
There are two main families of membrane receptor for ATP, the P2X and P2Y receptors. P2X receptors are ATPgated channels formed by the association of three subunits (Khakh and Alan North, 2006; Kawate et al., 2009). The seven P2X subunits can form homomeric or heteromeric channels, the later with different stoichiometries (Compan et al., 2012). Despite their identification more than 20 years ago, pharmacology of P2X receptors still remains limited. Indeed, because of their widespread expression, of our partial understanding of their subunit composition and the relative paucity of pharmacological tools, deciphering the physiology of P2X receptors is still challenging. Extracellular ATP also activates a subset of G protein coupled $\mathrm{P} 2 \mathrm{Y}$ receptors (von Kügelgen and Harden, 2011), mainly P2Y1, P2Y2, and P2Y11, although these receptors display higher affinity for other endogenous nucleotide such as ADP or UTP (von Kügelgen, 2019). However, activation of P2Y receptors by ATP seems to have important physiological functions, particularly in the central nervous system (Weisman et al., 2012). Pharmacology of $\mathrm{P} 2 \mathrm{Y}$ receptors is considerably more developed than that of P2X receptors (Jacobson and Müller, 2016). However, because these proteins are coupled to intracellular signaling pathways, studying the dynamic of their activation in integrated preparation mostly relies on indirect readthrough.

Studying extracellular ATP signaling in multicellular preparations and in vivo is complex. First, in vertebrate virtually all cells can release ATP through various mechanisms such as classical vesicular release, lysosomal exocytosis, transmembrane channels, or cell lysis (Praetorius and Leipziger, 2009; Lohman et al., 2012; Rassendren and Audinat, 2016). Signals triggering ATP release remain poorly characterized, although there is clear evidence that cells constitutively release ATP (Lazarowski et al., 2011; Sivaramakrishnan et al., 2012) and that evoked release can be triggered in defined physiological and pathologic contexts (Lazarowski, 2008). A second level of complexity comes from the short half-life of extracellular ATP. Because of the ubiquitous expression of membranebound and soluble ectonucleotidases, extracellular ATP is within seconds to minutes degraded in ADP and ultimately adenosine, which both also act as signaling molecules (Deaglio and Robson, 2011; Kukulski et al., 2011).

This work was supported by the Agence National de la Recherche Grant ANR-14-CEE11-0004-01 and the LabEx ICST Grant ANR-11-LABX-0015.

*V.C. and F.R. are equally participating senior authors.

Acknowledgment: We thank the iExplore animal facility (Institut de Génomique Fonctionnelle, Montpellier) and the Arpege plateform (Institut de Génomique Fonctionnelle, Montpellier) for the use of plate reader for cellpopulation fluorescence. We also thank Hélène Hirbec for her assistance with statistical analysis, Julie Perroy for sharing video-microscopy equipment, and Etienne Audinat for critical reading of this manuscript.

Correspondence should be addressed to Francois Rassendren at francois. rassendren@igf.cnrs.fr or Vincent Compan at Vincent.compan@igf.cnrs.fr.

https://doi.org/10.1523/ENEURO.0185-20.2020 Copyright (C) 2021 Ollivier et al.

This is an open-access article distributed under the terms of the Creative Commons Attribution 4.0 International license, which permits unrestricted use, distribution and reproduction in any medium provided that the original work is properly attributed.
Various methods have been developed to measure extracellular ATP (Wu and Li, 2020). The most common is the luciferase-luciferin assay which allows bioluminescent quantification of ATP in solution. A genetically encoded version of this assay was developed (Pellegatti et al., 2005); however, because of its low quantic yield, this approach has limited applications and lacks spatio-temporal resolution. To assess ATP release in situ, electrochemical-based microelectrodes have been engineered. While these approaches provide a direct monitoring of extracellular ATP ex vivo, their spatial definition remains limited (Llaudet et al., 2005). Several genetically encoded extracellular ATP sensors have been engineered (Pellegatti et al., 2005; Richler et al., 2008; Conley et al., 2017; Lobas et al., 2019). They present several improvements to chemical-based assays by allowing precise cellular and plasma membrane targeting as well as bioluminescent or fluorescent output. However, these sensors have several limitations that restrict their use. First, these sensors display poor apparent affinity for ATP, often above $100 \mu \mathrm{M}$ and therefore are not sensitive enough to detect ATP concentration below $10 \mu \mathrm{m}$. Second, their kinetics are slow with $\tau$-on and $\tau$-off above $5 \mathrm{~s}$ at physiological ATP concentrations. These limitations considerably restrict their use ex vivo and in vivo where extracellular ATP rarely raises above ten of micromolar and is rapidly degraded by ectonucleotidases.

To overcome these limitations, we generated versatile P2X-GCaMP6s fusion proteins that allow reporting accurately, specifically and dynamically their activity. In addition, engineering gain-of-affinity mutations in P2X2GCaMP6s led to generate ATP sensors with nanomolar apparent affinity for ATP and fast kinetics.

\section{Materials and Methods}

\section{cDNA cloning and site-directed mutagenesis}

The GCaMP6s cDNA (gift from Douglas Kim and GENIE Project, Addgene plasmid \#40753) was subcloned in pWPT-EF1 $\alpha$-IRES-DsRed2 or pWPT-EF1 $\alpha$-P2A-mScarlet lentiviral vectors by enzymatic digestion. P2A-Scarlet (Bindels et al., 2017) was produced by gene synthesis (Eurofins Genomics) and directly subcloned in appropriate expression vector. For rat P2Xs-GCaMP6s fusions, GCaMP6s was PCR inserted in frame at the C-terminal tail of P2X subunits. P2X2-GCaMP6s cDNA was inserted in pWPT-EF1 $\alpha$-IRES-DsRed2, pWPT-EF1 $\alpha$-P2AmScarlet, or pWPT-CaMKII $\alpha$ lentiviral vectors by enzymatic digestion. A similar strategy was used to fuse P2X2 subunits with RCaMP2 (Inoue et al., 2015; gift from Perroy, Institut de Genomique Fonctionnelle, Centre National de la Recherche Scientifique, Montpellier, France) and jRGECO1a (gift from Douglas Kim and GENIE Project, Addgene plasmid \#61563), or other P2X subunits to GCaMP6s. Mutations were generated in the rat P2X2 receptor using the Q5 site-directed mutagenesis kit (NEB). Each mutation was verified by DNA sequencing and subcloned in pWPT-EF1 $\alpha$-P2X2-GCaMP6s-IRESDsRed2 or pWPT-EF1 $\alpha$-P2X2-GCaMP6s-P2A-mScarlet lentiviral vectors. 


\section{HEK-293T cells culture}

HEK-293T cells (ATCC CRL-3216) were maintained in DMEM-GlutaMax (ThermoFisher), 10\% fetal bovine serum (FBS; ThermoFisher) and 1\% penicillin-streptomycin (P/S; 10,000 U/ml, ThermoFisher). Cells were grown in a humidified atmosphere of $95 \%$ air $/ 5 \% \mathrm{CO}_{2}$ at $37^{\circ} \mathrm{C}$ in a cell culture incubator. Cells were split $1 / 10$ when the confluence reached $90 \%$, generally every $3-4 \mathrm{~d}$.

\section{HEK-293T cell transfections}

For GCaMP6s fluorescence recording, HEK-293T cells were plated in six-well plates $1 \mathrm{~d}$ before transfection. Cells were transfected, depending on the plasmid, with $0.1-1 \mu \mathrm{g}$ of plasmid for each well using Lipofectamine 2000 (ThermoFisher) according to the manufacturer's recommendation; $24 \mathrm{~h}$ after transfection, cells were split in poly-L-ornithine (Sigma) coated 96-well plate and incubated at $37^{\circ} \mathrm{C}$ for 24 or $48 \mathrm{~h}$ before imaging experiments. For co-transfections experiments, $0.5-1 \mu \mathrm{g}$ of plasmids was used for PG6, PKG6, and GCaMP6s, $60 \mathrm{ng}$ for TRPV1 and GluN2A, and 20 ng for GluN1. In experiments where GluN1/GluN2A were co-expressed, cells were maintained in $10 \mu \mathrm{m}$ D-AP5 (Tocris) to avoid cellular toxicity.

For patch clamp experiments, trypsin-treated HEK cells were seeded onto poly-lysine (Sigma) pretreated glass coverslips in 35-mm dishes $1 \mathrm{~d}$ before transfection and incubated at $37^{\circ} \mathrm{C}$ with $5 \% \mathrm{CO}_{2}$. Transfections were conducted using calcium phosphate precipitation using 0.1$0.3 \mu \mathrm{g}$ of P2X2 or P2X-GCaMP6s plasmids. For P2X2 experiments, $0.3 \mu \mathrm{g}$ of pCDNA3-GFP plasmid was added to identify putative co-expressing cells. Medium was changed $1 \mathrm{~d}$ after transfection and used within $24 \mathrm{~h}$.

\section{Lentivirus production}

Versene-treated HEK cells were seeded in $15-\mathrm{cm}$ plate at $60 \%$ confluence. One day later, cells were transfected with a combination of three plasmids: $5 \mu \mathrm{g}$ of pMD2.G (gift from Didier Trono, Addgene plasmids \#12259), $15 \mu \mathrm{g}$ of psPAX2 (gift from Didier Trono, Addgene plasmids $\# 12260$ ), and $20 \mu \mathrm{g}$ of the transfer plasmid. Transfections were conducted using calcium phosphate precipitation. Six hours after transfection, HEK cells were washed with fresh medium (DMEM GlutaMax + 1\% FBS + 1\% P/S). 72 $\mathrm{h}$ after transfection, the supernatant was collected and filtered $(0.45-\mu \mathrm{m}$ filter) to remove cellular debris. $40 \%$ polyethylene glycol solution (PEG6000, Sigma) $4 \times$ was added to the supernatant and incubated overnight at $4^{\circ} \mathrm{C}$ and centrifugated for $30 \mathrm{~min}$ at $2600 \times g$ at $4^{\circ} \mathrm{C}$. The pellet containing the lentiviral particles was resuspended in $100-\mu \mathrm{l}$ PBS, aliquoted, and stored at $-80^{\circ} \mathrm{C}$.

\section{Electrophysiological recordings}

Currents were recorded using the whole-cell configuration of the patch clamp technique only from fluorescent cells. Cells were maintained at a holding potential of $-60 \mathrm{mV}$. Patch pipettes ( $3-5 \mathrm{M} \Omega$ ) contained the following: $140 \mathrm{~mm} \mathrm{KCl,} 5 \mathrm{~mm} \mathrm{MgCl}$, 5 mm EGTA, and $10 \mathrm{~mm}$ HEPES,
$\mathrm{pH} 7.3$ adjusted with $\mathrm{NaOH}$ (maintained at 300 mOsm). External solution contained the following: $140 \mathrm{~mm} \mathrm{NaCl}$, $2.8 \mathrm{~mm} \mathrm{KCl}, 2 \mathrm{~mm} \mathrm{CaCl}_{2}, 2 \mathrm{~mm} \mathrm{MgCl}_{2}, 10 \mathrm{~mm}$ glucose, and $10 \mathrm{~mm}$ HEPES, pH 7.3 adjusted with $\mathrm{NaOH}$ (maintained at $300 \mathrm{mOsm})$, containing or not ATP, and was delivered through three parallel tubes placed immediately above the cell. These tubes are displaced horizontally with the aid of a computer-driven system (SF 77A Perfusion fast step, Warner) that ensures solution exchange in 5-10 ms. ATP (sodium salt, Sigma) was applied briefly (2 s), and for high ATP concentrations, $\mathrm{pH}$ was carefully adjusted with $\mathrm{NaOH}$.

\section{Neuronal primary culture and transductions}

Detailed protocol of the culture has been already described (Moutin et al., 2020). Hippocampi from newborn C57BI/6J mice (P0 to P1) of either sex were collected in Hibernate-A medium (ThermoFisher) $+1 \% \mathrm{P} / \mathrm{S}$, digested using $0.1 \%$ papain at $37^{\circ} \mathrm{C}$ for $10 \mathrm{~min}$ and for five additional minutes in presence of DNAse1 $(1 \mathrm{mg} / \mathrm{ml}$, Roche). After stopping papain activity by adding $\mathrm{MC}+$ media, a Neurobasal-A based medium supplemented with $2 \%$ B27, $0.25 \%$ Glutamax, $0.5 \mathrm{~mm}$ L-glutamine (all from ThermoFisher), $1 \% \mathrm{P} / \mathrm{S}, 10 \% \mathrm{FBS}$, the tissue was mechanically dissociated using p1000 pipette. Dissociated tissue was centrifugated for $7 \mathrm{~min}$ at $300 \times g$, cells were resuspended in $\mathrm{MC}+$ media and were seeded in laminin and poly-L-ornithine precoated dishes (lbidi) and incubated at $37^{\circ} \mathrm{C}$. At DIV2, $1 \mu \mathrm{m} \mathrm{AraC}$ was added to reduce glial cell proliferation. At DIV3 the media was replaced by a BrainPhys based media (Stemcell technology) supplemented with $2 \%$ B27, $0.25 \%$ Glutamax, $1 \%$ P/S. At 7 days in vitro (DIV7), cultures were transduced using $6 \mu \mathrm{l}$ of lentiviruses for a 35-mm dish.

\section{Synaptosomes, plasma membrane biotinylation, and Western blotting}

For synaptosomes experiments, transduced neurons were washed twice with PBS supplemented with $1 \mathrm{~mm}$ $\mathrm{CaCl}_{2}$ and $0.5 \mathrm{~mm} \mathrm{MgCl}_{2}$ (PBS-CM) and lysed in Syn-PER reagent (ThermoFisher) mixed with protease inhibitor cocktail (ThermoFisher). Lysates were centrifugated for $10 \mathrm{~min}$ at $1200 \times g$ at $4^{\circ} \mathrm{C}$. Supernatant was transferred in a new tube and $30 \mu \mathrm{l}$ was kept as the homogenate fraction. The remaining supernatant was centrifugated for $20 \mathrm{~min}$ at $15,000 \times g$ at $4^{\circ} \mathrm{C}$. $30 \mu \mathrm{l}$ of the supernatant was kept as the cytosolic fraction. The pellet was resuspended in $30 \mu \mathrm{l}$ Syn-PER reagent and was kept as the synaptic fraction. Samples were diluted in LDS-Page $4 \times$ denaturant buffer (Invitrogen) supplemented with 5\% $\beta$-mercaptoethanol and heated for $5 \mathrm{~min}$ at $80^{\circ} \mathrm{C}$.

For biotynilation experiments, neurons were washed twice with PBS-CM and labeled using $1 \mathrm{mg} / \mathrm{ml}$ sulfoNHS-LC-Biotin (Pierce) for $30 \mathrm{~min}$ at $4^{\circ} \mathrm{C}$ in PBS-CM. Cells were washed three times in PBS-CM supplemented with $10 \mathrm{~mm}$ Tris $\mathrm{pH} 7.4$ to quench free reactive biotin. Cell lysis was performed for $30 \mathrm{~min}$ at $4^{\circ} \mathrm{C}$ under agitation in cell lysis buffer (100 mm NaCl, $20 \mathrm{~mm}$ HEPES pH 7.4, $5 \mathrm{~mm}$ EDTA, 1\% Triton X-100) mixed with protease inhibitors. 
Lysates were centrifuged $\left(13,000 \times \mathrm{g}, 10 \mathrm{~min}, 4^{\circ} \mathrm{C}\right)$ and the supernatants collected. Biotinylated proteins were purified with Neutradivin coated magnetic beads (Spherotech) for $1 \mathrm{~h}$ at room temperature. After three washes with cell lysis buffer + protease inhibitor, proteins were eluted in LDS-Page $4 \times$ denaturant buffer (Invitrogen) supplemented with $5 \% \beta$-mercaptoethanol and heated for $5 \mathrm{~min}$ at $80^{\circ} \mathrm{C}$.

Proteins were resolved on gradient $4-12 \%$ Nu-PAGE gels (ThermoFisher) in MOPS buffer (ThermoFisher) and then transferred to a nitrocellulose membrane with the iBlot system (ThermoFisher). Membranes were blocked with $0.1 \%$ Tween 20 in PBS (PBST) $+5 \%$ non-fat milk for $1 \mathrm{~h}$ at room temperature before incubating with primary antibody: anti-GFP $(1: 1,000$, Biolabs) or anti-actin $(1: 5,000$, DSHB) overnight at $4^{\circ} \mathrm{C}$. Membranes were washed and incubated with the appropriate HRP-conjugated secondary antibody $(1: 10,000)$ for $2 \mathrm{~h}$ at room temperature, then rinsed in PBS-T, and revealed with SuperSignal West Pico substrate (ThermoFisher). Signals were acquired with a Chemidoch touch (Bio-Rad) and analyzed with ImageLab.

\section{Immunocytochemistry}

At DIV15-DIV18, neurons on coverslips were washed twice with PBS, fixed with $4 \%$ formaldehyde in PBS for $5 \mathrm{~min}$ at room temperature, and then washed three times with PBS for $5 \mathrm{~min}$. Cells were blocked and permeabilized in PBS solution supplemented with $3 \%$ bovine serum albumin and $0.1 \%$ Triton X-100 (PBS-Perm) for $2 \mathrm{~h}$ at room temperature. After overnight incubation at $4^{\circ} \mathrm{C}$ in PBSPerm with rabbit anti-GFP (1:1,000, Biolabs) and mouse anti-MAP2 (1:2,000, Sigma) cells were washed and incubated with appropriate fluorescence-conjugated secondary antibodies $(1: 1,000$, Invitrogen) for $2 \mathrm{~h}$ at room temperature, then rinsed in PBS-Perm and incubated for 2 min with 300 nm DAPI diluted in $\mathrm{H}_{2} \mathrm{O}$. Coverslips were mounted on slides with a fluorescent mounting medium (DAKO). Images were acquired with an Axio Imager Z1 Apotome microscope (Zeiss) with $60 \times$ objective lens (Zstack with $Z$ spacing of $1 \mu \mathrm{M})$. Raw images were treated using ZEN software and maximum intensity projections of these images are shown.

\section{Plate reader recording}

Transfected HEK cells seeded in 96-well plates were washed twice and incubated in FLEX buffer [HBSS (ThermoFisher): 20 mM HEPES, pH 7.4, $1 \mathrm{~mm} \mathrm{MgSO}_{4}, 3$ $\mathrm{mm} \mathrm{Na}_{2} \mathrm{CO}_{3}$, supplemented with $1.3 \mathrm{mM} \mathrm{CaCl}$ ] for $15 \mathrm{~min}$ at $37^{\circ} \mathrm{C}$. For dose-response and pharmacological experiments, $2 \times$ concentrated drugs in FLEX buffer were delivered to the well. For dose response experiments performed on neurons, FLEX buffer was replaced by ACSF buffer ( $150 \mathrm{~mm} \mathrm{NaCl}, 2 \mathrm{~mm} \mathrm{CaCl} 2,3 \mathrm{~mm} \mathrm{KCl,} 10$ mM HEPES, pH 7.4, and $10 \mathrm{~mm}$ D-glucose). For experiments without extracellular calcium, cells were incubated for $15 \mathrm{~min}$ in the FLEX buffer without $\mathrm{CaCl}_{2}+1 \mathrm{~mm}$ EGTA (ThermoFisher). For hypotonicity experiments, $\mathrm{H}_{2} \mathrm{O}$ Milli-Q water $+1.3 \mathrm{~mm} \mathrm{CaCl}_{2}$ were added to the well to obtain 240 or $160 \mathrm{mOsm}$ solutions. The osmotic concentration of each solution was verified with an osmometer. Fluorescence ( $\lambda$ exc/em 485/540) was acquired with either a FlexStation3 (Molecular Devices) equipped with automatic injectors or with an INFINITY 500 (TECAN) plate reader. Recording was performed at 1 or $0.15 \mathrm{~Hz}$ for the Flexstation three and the INFINITY 500 , respectively. All the experiments were performed at $37^{\circ}$ C.

\section{Time-lapse imaging}

Video-microscopy experiments were performed on primary cultured neurons at DIV15-DIV18, at least $10 \mathrm{~d}$ after transduction. Neurons were washed and incubated in ACSF buffer. ACSF osmolarity was carefully adjusted to 320 mOsm using $\mathrm{NaCl}$. External solution was delivered through a perfusion system allowing fast and local drug application. ATP (sodium salt, Sigma) and other compounds were applied briefly (10 s) except for ionomycin which was applied for several minutes. All cells were imaged using an epifluorescence microscope (OLYMPUS IX70) equipped with an Evolve photometrics camera with a $20 \times$ water-immersion objective lens. Acquisitions were performed at $1 \mathrm{~Hz}$ ( $\lambda$ exc/em 485/540). The microscope was driven by MetaMorph software and data were analyzed with ImageJ. For images analysis, a region of interest (ROI)-based analysis was performed with ImageJ. For primary neurons, each value is an average of two to three ROls localized in the dendrites and one ROI localized in the cellular body.

ON-time constants were obtained at room temperature by recording fluorescence in HEK cells at $100 \mathrm{~Hz}$ using an Axiovert $200 \mathrm{M}$ microscope (Zeiss) equipped with a Plan-Neofluar $40 \times / 1.3$ oil objective (Zeiss), an evolve camera (Photometrics) equipped with an EMCCD detector. Fluorescence emission was acquired using a 440/ $20 \mathrm{~nm}$ LED and a LP 515 Filter (Zeiss) emission filter. Activation times constant were manually calculated as the time to reach $50 \%$ of the maximal fluorescence.

\section{ATP dosage by bioluminescence}

ATP was detected by bioluminescence with the CellTiterGlo 2.0 ATP kit (Promega) based on the manufacturer's recommendation. Briefly, HEK cells were seeded in 24-well plate at a density of $2.5 \times 10^{5}$ per well. Experiments were performed $24 \mathrm{~h}$ later. After a 50\% osmotic choc (160 mOsm), an equivalent volume of the CellTiter-Glo reagent and cell supernatant were mixed in a 96-well plate, incubated for $5 \mathrm{~min}$ at room temperature and shake for $2 \mathrm{~min}$ at $37^{\circ} \mathrm{C}$. The bioluminescence was quantified with a plate reader (INFINITY 500). In parallel, the quantity of cells was estimated by a BCA protein assay and the concentration of ATP released was expressed relative to the amount of protein.

\section{Statistical analysis}

Data are presented as the mean \pm SEM from the number of experiment (data from three or more independent experiments). Data were analyzed using Prism software (GraphPad) either by an unpaired two tailed Student's $t$ test to determine difference between two groups, or one- 
way ANOVA with appropriate multiple-comparison test to determine difference between more than two groups.

\section{Results}

P2X2-GCaMP6s fusion (stated below as PG6) was engineered by fusion of GCaMP6s, a genetically encoded calcium indicator (GECl) with improved kinetics, dynamic range and affinity for calcium (Chen et al., 2013) to the Cterminal tail of rat P2X2. We expected that on receptor activation, calcium influx through P2X2 pore will specifically trigger GCaMP6s fluorescence as previously described using a FRET-based GECl (Richler et al., 2008; Fig. 1A). Functional properties of P2X2 and PG6 were compared by whole-cell recording in transfected HEK cells. We observed no difference in the apparent affinity for ATP of the two receptors or in their kinetics of activation and inactivation, although these later parameters were not investigated thoroughly (Fig. 1B,C). Upon $10 \mu \mathrm{M}$ ATP application a strong increase of fluorescence near the plasma membrane was observed in HEK cell transfected with PG6 (Fig. 1D), while basal fluorescence was very low and did not change on application of vehicle.

We next used a plate reader assay combined with fast automated injection system to further characterize ATPevoked fluorescence in PG6 transfected HEK cells. ATP dose-response experiment revealed an $\mathrm{EC}_{50}$ of $2.4 \pm 0.3$ $\mu \mathrm{M}(\mathrm{N}=4)$ and Hill coefficient $(\mathrm{nH})$ of $1.7 \pm 0.2$ with a dF/F of $1.3 \pm 0.3$ at $10 \mu \mathrm{m}$ ATP (Fig. $1 E, J)$. Activation time constants were analyzed in HEKs cell using video microscopy at an acquisition rate of $100 \mathrm{~Hz}$. ON-time constants of ATP-evoked fluorescence show concentration-dependent relationship reaching $586.1 \pm 17$ and $261.5 \pm 15 \mathrm{~ms}$ $(n=13)$ at 1 and $10 \mu \mathrm{M}$, respectively (Fig. $1 F)$. Calcium influx through the P2X2 channel was responsible for GCaMP6s fluorescence, since removal of extracellular calcium completely abolished ATP-evoked signal (Fig. $1 G)$. The contribution to fluorescence signal by calcium released from intracellular stores following activation of endogenous P2Y receptors by ATP was evaluated in HEK cells transfected with P2X2-K69A-GCaMP6s (stated bellow as PKG6), a biosensor in which the lysine 69 that contributes to the ATP-binding site was mutated to alanine (Jiang et al., 2000). In these cells, application of increasing ATP concentrations only evoked a minimal calcium signal (Fig. $1 H, J)$. By comparison, in HEK cells expressing a cytosolic GCaMP6s, ATP-evoked endogenous P2Y activation resulted in a strong fluorescence signal with an $\mathrm{EC}_{50}$ of $10.6 \pm 4 \mu \mathrm{M}, \mathrm{nH}=1.5(N=4$; Fig. $1 /, J)$, supporting that fluorescence signal evoked by PG6 activation is minimally contaminated by calcium release from internal stores.

We also analyzed whether calcium influx through other ion channels localized at the plasma membrane could contribute to PG6 fluorescence. We first co-expressed in HEK cells PG6 with GluN1 and GluN2A subunits of the NMDA receptor, a ligand-gated channel with significant calcium permeability. In these cells, application of $50 \mu \mathrm{m}$ NMDA and $10 \mu \mathrm{m}$ glycine evoked a small fluorescence signal $(20.3 \pm 3.9 \%, n=3)$ of that evoked by $10 \mu \mathrm{m}$ ATP (Fig. 2A,E). A similar signal was obtained in cells co-expressing PKG6 and GluN1/GluN2A subunits
$(16.7 \pm 4.5 \%, n=3$; Fig. $2 B, E)$. By comparison, in HEK cells co-expressing GluN1/GluN2A and the cytosolic GCaMP6s, both NMDA/glycine and ATP application evoked strong fluorescence signals indicating that calcium influx through NMDA channel marginally activates PG6 (Extended Data Fig. 2-1A). Similar experiments were performed by co-expressing TRPV1 and PG6. In this case, $100 \mathrm{~nm}$ capsaicin application induced a fluorescence signal of $31.9 \pm 8.1 \%$ of the fluorescence evoked by $10 \mu \mathrm{m}$ ATP (Fig. $2 C, F$ ). In cells coexpressing TRPV1 and PKG6, capsaicin (100 nM) and ATP $(10 \mu \mathrm{M})$ evoked fluorescence signals were $18.4 \pm 5.3 \%$ and $8.1 \pm 2.9 \%$ (Fig. $2 D, F$ ). Here, also, in HEK cells co-expressing TRPV1 and the cytosolic GCaMP6s, both capsaicin and ATP application evoked strong fluorescence signals (Extended Data Fig. 2-1B). NMDA and capsaicin evoked fluorescence in PG6 and PKG6-expressing cells were not significantly different, yet both signals were significantly smaller than fluorescence evoked by $10 \mu \mathrm{M}$ ATP in PG6-expressing cells (Fig. 2E,F). Together, these results support that PG6 fluorescence signal is mainly triggered by calcium influx through the pore of the channel and that any other sources of intracellular calcium increase marginally contribute to the fluorescence signal.

The fusion strategy was extended to other P2X subunits, which were linked to GCaMP6s by C-terminal fusion. Among the six subunits individually expressed in HEK cells, dose-dependent ATP evoked fluorescence signals were observed for P2X4, P2X5, and P2X7 (Fig. 3A-C). Apparent affinities for ATP were 1.2 $\pm 0.3,8.1 \pm 3.1$, and $72.3 \pm 28 \mu \mathrm{M}$ for P2X4, P2X5, and P2X7, respectively (Fig. $3 E, F)$. In the case of $P 2 X 7$, a higher apparent affinity of $5.2 \pm 2.5 \mu \mathrm{m}$ for BzATP was observed (Fig. 3C,E). No fluorescence signal was observed for P2X1 and P2X3 presumably because the rapid desensitization rates of these two receptors are faster than the acquisition frequency of the plate reader $(1 \mathrm{~Hz})$. Regarding P2X6, this subunit does not form functional homomeric channel (Fig. 3D). As previously shown for PG6, ATP-evoked fluorescence at P2X4-GCaMP6s was abolished in the absence of extracellular calcium (Extended Data Fig. 3-1B) and mutation of ATP binding site (P2X4-K69A-GCaMP6s) significantly reduced ATP-evoked fluorescence, although ATP concentrations above $10 \mu \mathrm{m}$ evoked fluorescence signals stronger than observed for PKG6 (Extended Data Fig. 3$1 A, C)$, presumably because internalized $\mathrm{P} 2 \mathrm{X} 4$ receptors might be more sensitive to P2Y-evoked cytosolic calcium increase (Bobanovic et al., 2002).

We next asked whether ATP biosensors could be used to investigate ATP signaling in neurons. To that aim we generated lentiviruses expressing either PG6 or PKG6 under the control of the CaMKIl $\alpha$ promoter to transduce primary culture of hippocampal neurons. Expression and subcellular localization of PG6 were analyzed by immunocytochemistry and Western blotting. PG6 is present in neuronal cell body as well as in dendritic compartment as shown by the colocalization of GFP and MAP2 immunostaining (Fig. 4A). Both PG6 and PKG6 are expressed at the plasma membrane, as demonstrated by cell surface 

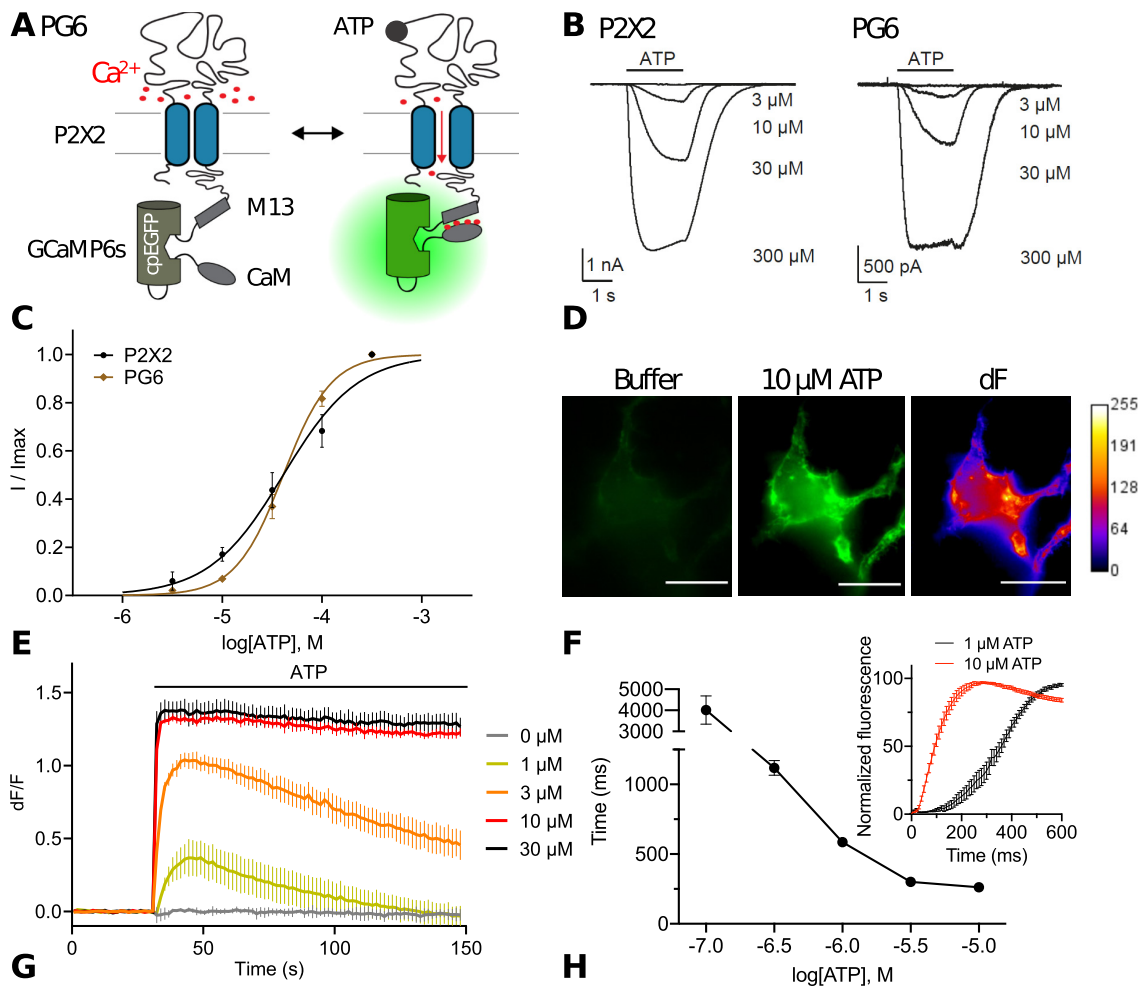

$\mathbf{F}$
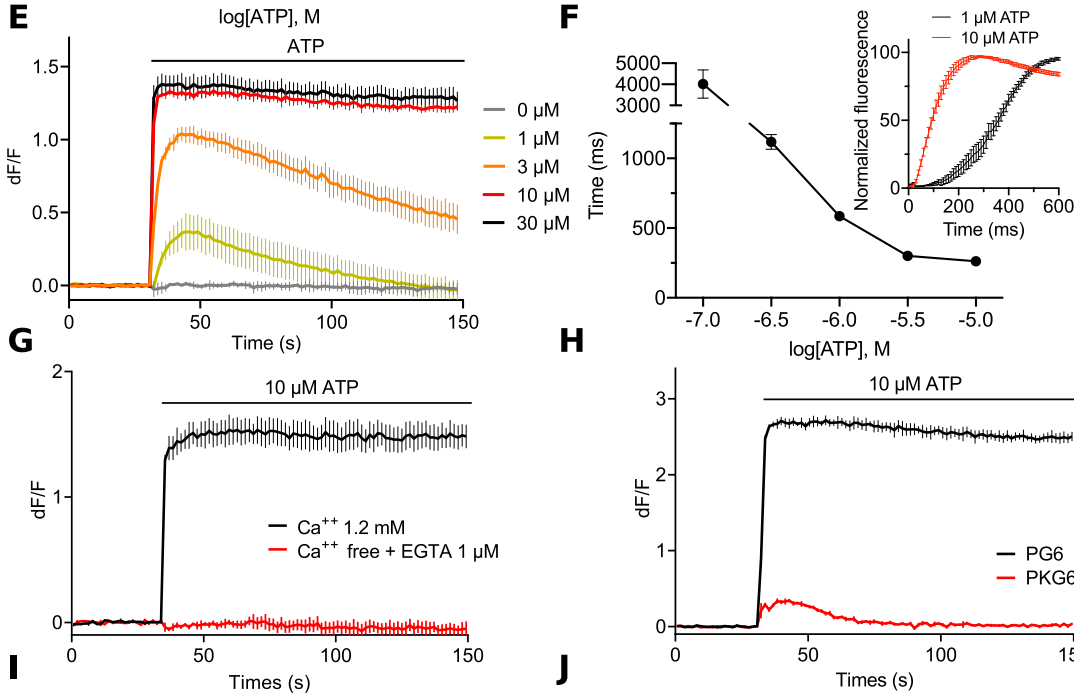

H
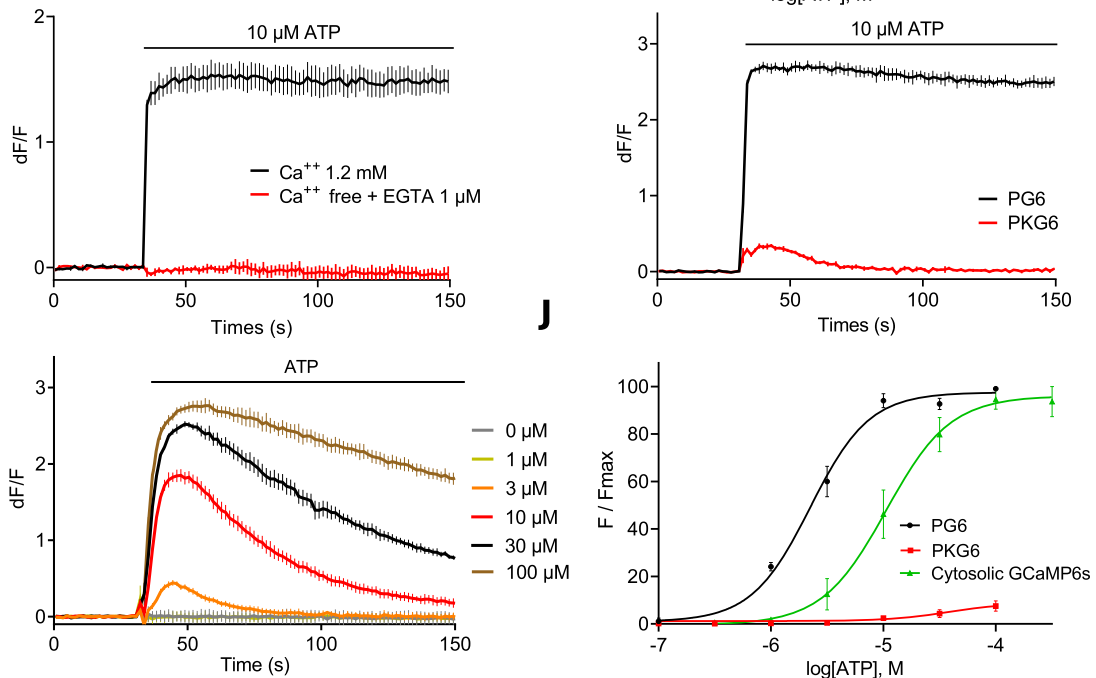

Figure 1. P2X2-GCaMP6s (PG6) fusion is functional and displays concentration-dependent ATP-evoked fluorescence changes. $\boldsymbol{A}$, Cartoon illustrating the biosensor and the change in GCaMP6s fluorescence during P2X2 activation. $\boldsymbol{B}, \boldsymbol{C}$, Representative traces $(\boldsymbol{B})$ and normalized dose-response curves $(\boldsymbol{C})$ of ATP evoked current measured by whole-cell recording in HEK cells expressing WT P2X2 receptors or PG6 fusion. $\boldsymbol{D}$, Representative images showing fluorescence changes ( $\lambda$ exc/em 485/540) of a HEK cell expressing PG6 after ATP application $(10 \mu \mathrm{m})$. Images show pseudo-colored dF after F0 subtraction. Scale bar: $20 \mu \mathrm{m}$. E, Example traces generated from a plate reader of changes in $\mathrm{dF} / \mathrm{F}$ values triggered by increasing concentration of ATP in HEK cells expressing PG6. $\boldsymbol{F}$, PG6 time constant of activation $(\tau \mathrm{ON})$ as a function of ATP concentration. PG6 was expressed in HEK cells and fluorescence evoked by increasing ATP concentration was acquired by video microscopy at $100 \mathrm{~Hz}$. ON-time constants were calculated from $N=3$ independent experiments and $n>6$ cells per experiments. Inset shows representative fluorescence change evoked by $1 \mu \mathrm{M}$ (black trace) and $10 \mu \mathrm{m}$ (red trace) ATP. G, $\boldsymbol{H}$, Representative traces from a plate reader of changes in dF/F values triggered by 10 $\mu \mathrm{m}$ ATP. HEK cells expressed either PG6 in presence or absence of extracellular calcium (G), or PG6 and PKG6 $(\boldsymbol{H})$. I, Representative traces from a plate reader of changes in $\mathrm{dF} / \mathrm{F}$ values triggered by increasing concentration of ATP in HEK cells expressing the cytosolic GCaMP6s. J, Normalized concentration-response curves for ATP evoked changes in F/Fmax at the PG6 and PKG6 fusions and cytosolic GCaMP6s. Curves were generated from $N>4$ independent experiments. Data are expressed as mean \pm SEM in all panels. For panels $\boldsymbol{E}, \boldsymbol{G}, \boldsymbol{H}, \boldsymbol{I}$, representative data from $n=3$ wells per condition. 
A GuN1/GuN2A/PG6

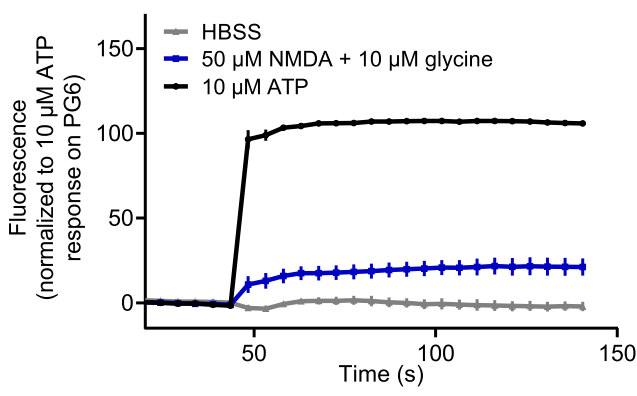

C TRPV1/PG6

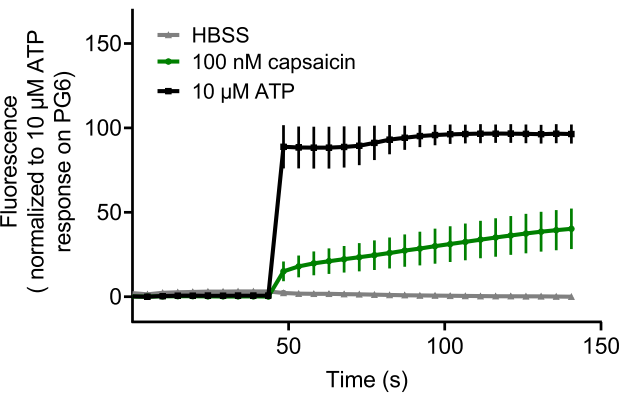

E

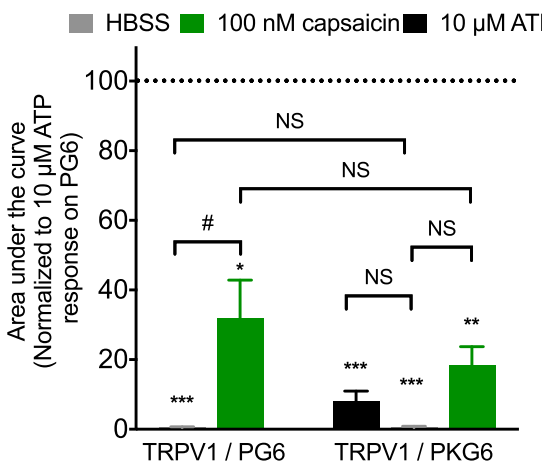

B GuN1/GuN2A/PKG6

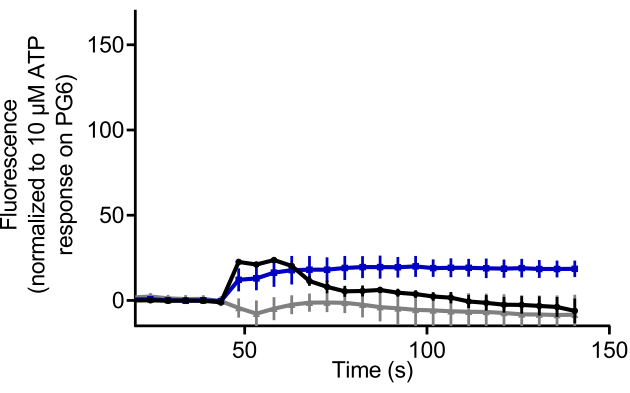

D TRPV1/PKG6
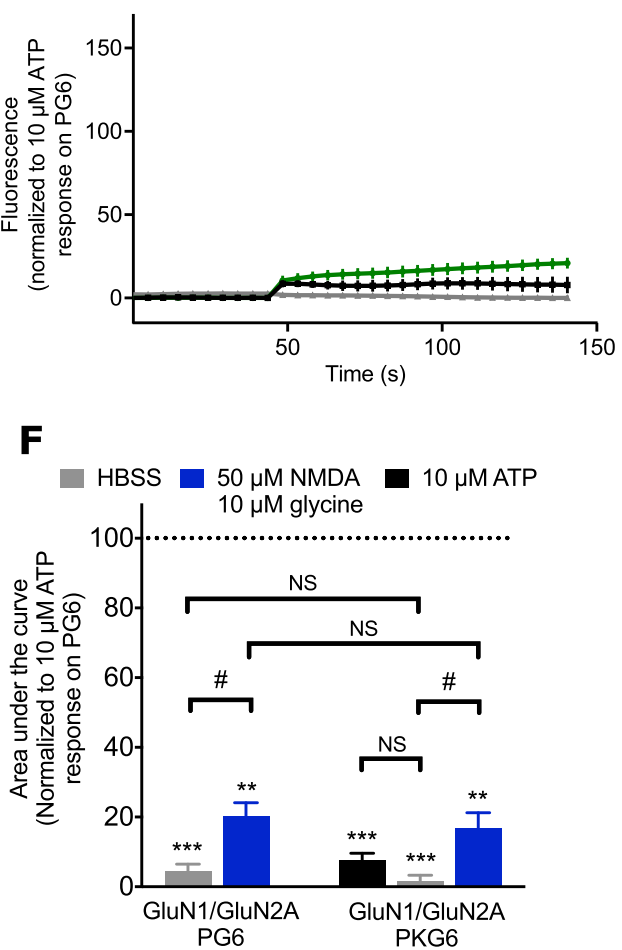

Figure 2. PG6 fluorescence signal is mainly triggered by calcium influx through the pore of the channel. $\boldsymbol{A}, \boldsymbol{B}$, Representative traces of normalized fluorescence changes evoked by ATP (10 $\mu \mathrm{M}$, black), HBSS (gray), or NMDA/glycine (50/10 $\mu \mathrm{M}$, blue) in HEK cells expressing NMDA receptor subunits GluN1 and GluN2A in combination with either PG6 $(\boldsymbol{A})$ or PKG6 $(\boldsymbol{B})$. Data were generated from a plate reader with $n=3$ wells per condition. $\boldsymbol{C}, \boldsymbol{D}$, Representative traces of normalized fluorescence changes evoked by ATP (10 $\mu \mathrm{M}$, black), HBSS (gray), or capsaicin (100 nm, green) in HEK cells expressing TRPV1 in combination either with PG6 (C) or PKG6 (D). Data were generated from a plate reader with $n=3$ wells per condition. $\boldsymbol{E}$. Plots of area under the fluorescence curve obtained from data shown in panels $\boldsymbol{A}$, $\boldsymbol{B}$. Values were normalized to response evoked by $10 \mu \mathrm{m}$ ATP in PG6-expressing cells. $\boldsymbol{F}$, Plot of area under the fluorescence curve obtained from data shown in panels $\boldsymbol{C}, \boldsymbol{D}$. Values were normalized to response evoked by $10 \mu \mathrm{m}$ ATP in PG6-expressing cells. In all panels, data are expressed as mean \pm SEM of $N \geq 3$ independent experiments; ${ }^{*} p<0.05,{ }^{* *} p<0.005,{ }^{* * *} p<0.001$, one-sample $t$ test compared with $100 \%$ reference value; \#p $<0.005$; NS, non-significant, one-way ANOVA with FDR corrected post hoc tests.

biotinylation and subsequent neutravidin pull down (Extended Data Fig. 4-1A). Further, subcellular fractionation reveals that PG6 and PKG6 are enriched in the synaptosomal fraction (Extended Data Fig. 4-1B,C).

ATP dose-response experiments showed little desensitization of fluorescence signal on prolonged agonist application and revealed a much higher sensitivity of PG6 to ATP compared with what was observed in HEK cells, with an $\mathrm{EC}_{50}$ of $0.22 \pm 0.11 \mu \mathrm{M}$ (Fig. 4B,C). Functional analysis by video microscopy confirmed that in neurons, PG6 can be activated by sub-micromolar ATP concentration. At
300 nм ATP stimulation, fluorescence showed rapid onset (below $1 \mathrm{~s}$ ) but slower offset (6 s). At higher ATP concentration, fluorescence offset signals developed even slower with a plateau response which eventually persisted even after ATP wash out (Extended Data Fig. 4-1D; Movie 1). It is not known whether this plateau was because of a longlasting activation of $\mathrm{PG} 6$ or whether depolarization evoked by sustained P2X2 activation can elicit additional calcium influx, contributing to GCaMP6s fluorescence.

We asked whether expression of PG6 in neurons could induce uncontrolled calcium entry either through direct 
A P2X4-GCaMP6s

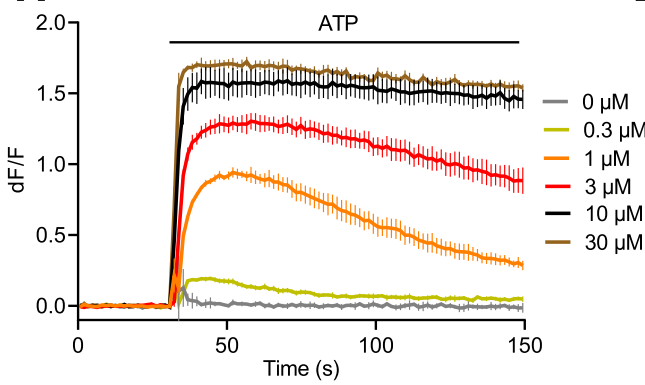

C P2X7-GCaMP6s
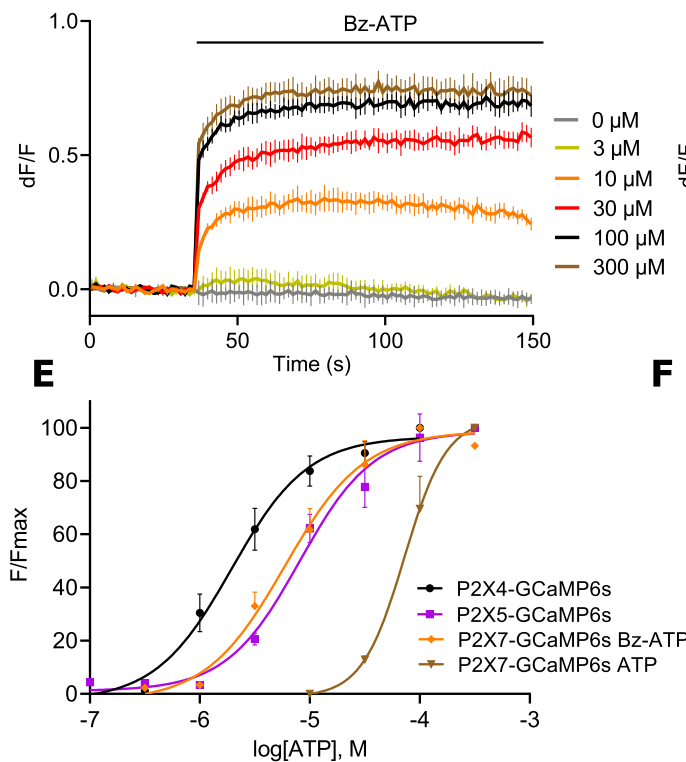

B P2X5-GCaMP6s

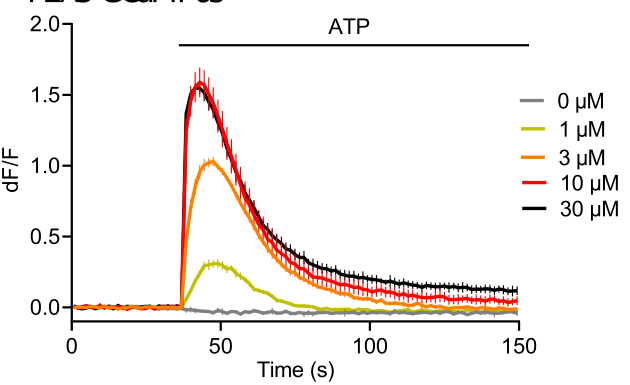

D P2X6-GCaMP6s

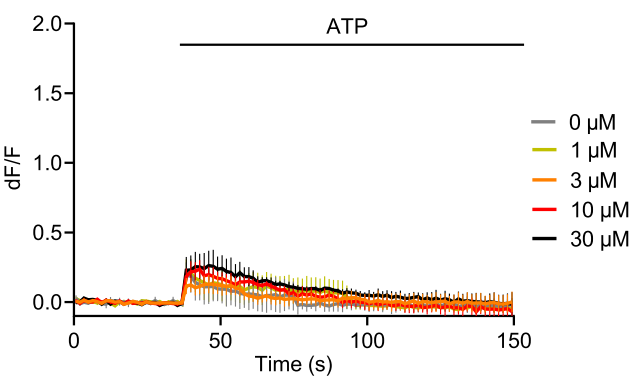

\begin{tabular}{lccc} 
Constructs & ATPEC50 $(\mu \mathrm{M})$ & $\mathrm{nH}$ & $\mathrm{dF} / \mathrm{F}$ \\
\hline P2X4-GCaMP6s & $1.2 \pm 0.3$ & $1.6 \pm 0.3$ & $1.8 \pm 0.4$ \\
\hline P2X5-GCaMP6s & $8.1 \pm 3.1$ & $1.3 \pm 0.6$ & $1.1 \pm 0.3$ \\
\hline P2X6-GCaMP6s & - & - & - \\
\hline P2X7-GCaMP6s & $72.3 \pm 28$ & $2.2 \pm 0.7$ & $0.3 \pm 0.02$ \\
\hline P2X7-GCaMP6s (Bz-ATP) & $5.9 \pm 2.5$ & $1.2 \pm 0.3$ & $0.6 \pm 0.1$ \\
\hline
\end{tabular}

Figure 3. P2X-GCaMP6s fusion strategy extended to others $\mathrm{P} 2 \mathrm{X}$ receptors. $\boldsymbol{A}-\boldsymbol{D}$, Representative traces of changes in $\mathrm{dF} / \mathrm{F}$ values triggered by increasing concentration of ATP $(\boldsymbol{A}, \boldsymbol{B}, \boldsymbol{D})$ or Bz-ATP $(\boldsymbol{C})$ in HEK cells expressing P2X4-GCaMP6s $(\boldsymbol{A})$, P2X5-GCaMP6s $(\boldsymbol{B})$, P2X7-GCaMP6s $(\boldsymbol{C})$ or P2X6-GCaMP6s $(\boldsymbol{D})$. Data were generated from a plate reader with $n \geq 3$ wells per condition. $\boldsymbol{E}$, Normalized concentration-response curves for ATP or Bz-ATP evoked changes in F/Fmax at the P2X4-, P2X5-, P2X6-, and P2X7GCaMP6s fusions. Curves were generated from $N=3$ independent experiments. Data are expressed as mean \pm SEM in all panels. $\boldsymbol{F}$, Summary of $\mathrm{EC}_{50}, \mathrm{nH}$, and maximal dF/F for P2X4-, P2X5-, P2X6-, and P2X7-GCaMP6s fusions expressed in HEK cells.

calcium entry trough $\mathrm{P} 2 \mathrm{X}$ pore or following endogenously release ATP and subsequent depolarization. To that aim we use c-Fos as a readout of neuronal activity. We analyzed whether neuronal PG6 expression would result in a stronger c-Fos expression compared with untransduced neurons. We found no difference between the two cell populations, c-Fos being not present in resting (unstimulated conditions), while both populations similarly responded to brain-derived neurotrophic factor (BDNF; Extended Data Fig. 4-1E,F).

We next investigated a potential activity-dependent ATP release. We reasoned that $\mathrm{KCl}$-evoked neuronal depolarization should elicit endogenous ATP release that could be detected by PG6 sensor. Hippocampal neuronal cultures were transduced as above either with PG6 or PKG6. Functional expression of the wild-type (WT) sensor was first tested by 10 -s application of $3 \mu \mathrm{M}$ ATP followed by successive 10-s applications of 25 and $50 \mathrm{~mm} \mathrm{KCl}$. In neurons expressing PG6, KCl-evoked depolarization induced transient fluorescence increase which intensity depends on the concentration of KCl (Fig. 4E). These increases of fluorescence were specifically due to direct ATP activation of the sensor since in neurons expressing PKG6, KCl applications evoked only minimal changes of fluorescence (Fig. 4E, red trace). As shown on Figure $4 F$, the changes in fluorescence evoked by $25 \mathrm{~mm} \mathrm{KCl}$ or by $3 \mu \mathrm{m}$ ATP applications were not statistically different, suggesting that neuronal depolarization results in ATP release that can reach few micromolar at the plasma membrane. These results indicate that PG6 acts as an ATP biosensor with a sensitivity below the micromolar range.

We next thought to improve the sensitivity of the PG6 biosensor by introducing point mutations which enhance ATP potency for P2X2 receptor (Li et al., 2004). Five point mutations were individually introduced in PG6: 140A, I328A, P329A, N333A, and V343A, and ATP potency for these different mutants were compared with that of the WT sensor (Fig. 5A-C). Out of these five mutants, ATP displayed a significant gain of potency for three of them: I328A, P329A, and N333A with $\mathrm{EC}_{50}$ S of $0.204 \pm 0.03$, $0.278 \pm 0.07$, and $0.327 \pm 0.04 \mu \mathrm{M}$, respectively. Maximal ATP-evoked fluorescence intensities of these mutants were different (Fig. 5B). Normalization of fluorescence 
A

a-MAP2 a-GFP DAP1
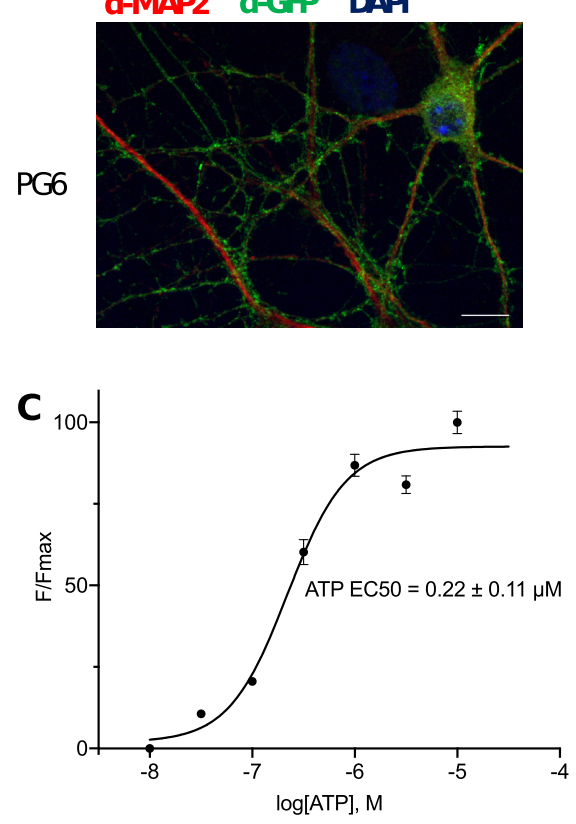

E

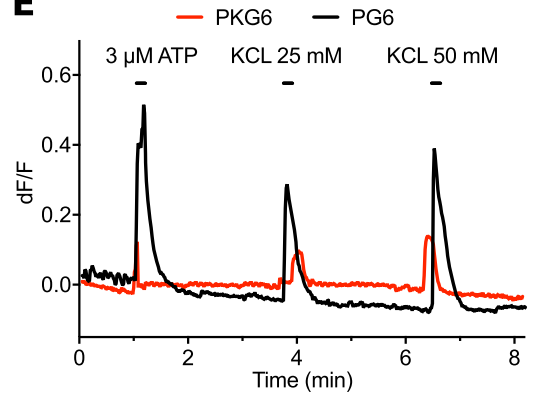

B

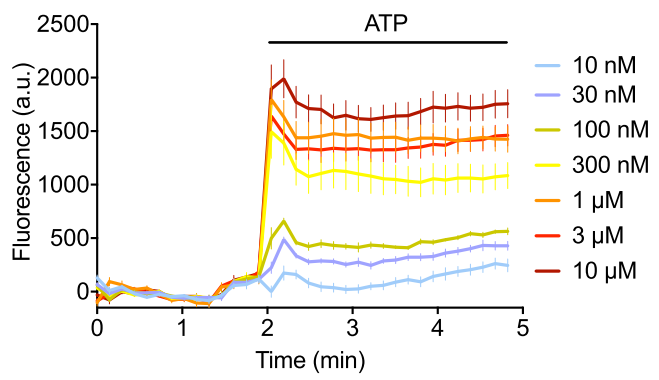

D

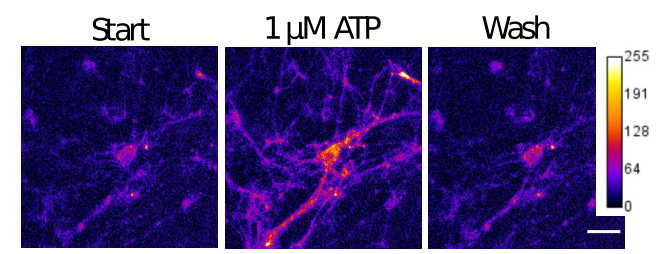

Figure 4. Expression and functional analysis of ATP sensors in hippocampal neurons. Neurons were transduced with a lentivirus expressing PG6 or PKG6 under the control of the CamKIl $\alpha$ promoter. $\boldsymbol{A}$, Transduced neurons were stained using antiGFP (green) and MAP2 (red) antibodies and nucleus was stained with DAPI (blue). PG6 is localized in the whole dendritic tree as well as in varicosities. Scale bar: $20 \mu \mathrm{m}$. B. Fluorescence changes generated from a plate reader and triggered by increasing concentration of ATP in hippocampal neurons expressing PG6. Data are expressed as mean \pm SEM of $N=2$ independent experiments and three wells per point. $\boldsymbol{C}$, Normalized concentration-response curves for ATP evoked fluorescence in neurons expressing PG6. Curves were generated from the data presented in B and are expressed as mean \pm SEM. $\boldsymbol{D}$, Representative images of ATP-evoked fluorescence. Intensity of fluorescence was color coded. Scale bar: $20 \mu \mathrm{m}$. $\boldsymbol{E}$, Representative fluorescence recording of $\mathrm{KCl}$-evoked activation of PG6 (black trace) and PKG6 (red trace) in neurons; $3 \mu \mathrm{M}$ ATP was first applied as above followed by 25 and $50 \mathrm{~mm} \mathrm{KCl}$. Fluorescence was acquired as above. KCl-evoked depolarization induced ATP release which in turn activated PG6. In neuron expressing PKG6, only a small and transient fluorescence signal was evoked by depolarization. For PG6 and PKG6, $N=2$ independent experiments, $n>12$ neurons. $\boldsymbol{F}$, Plot of area under the curves obtained from panel $\boldsymbol{E}, \boldsymbol{F}$. One-way ANOVA with Tukey's multiple comparisons test, ${ }^{\star *} p<0.01,{ }^{* \star *} p<$ $0.001,{ }^{* \star \star \star} p<0.0001$.

intensities to that of PG6 shows that maximal intensities of N333A and I40A were close to that of WT, while that of P329A was intermediate at $69.9 \%$ [95\% confidence interval $(\mathrm{Cl}) 61.3,81.1]$, and $1328 \mathrm{~A}$ and $\mathrm{V} 343 \mathrm{~A}$ clearly reduced at $34.9 \%(\mathrm{Cl} 30,41.5)$ and $29.7 \%(\mathrm{Cl} 26.7,33)$, respectively. Only P2X2-N333A-GCaMP6s (stated below as PNG6) and P2X2-P329A-GCaMP6s (PPG6) were further considered. As illustrated in Figure $5 D, E$, application of 300 nм ATP triggers strong fluorescence signals in cells expressing PNG6 and PPG6 $(\mathrm{dF} / \mathrm{F}=0.43 \pm 0.04$ and $0.33 \pm 0.08$, respectively) but not in cells expressing PG6.
Functional properties of PNG6 and PPG6 were also investigated by whole-cell recording in HEK cells. Compared to WT sensor, ATP activated currents at PNG6 and PPG6 with similar activation kinetics but somehow apparent slower deactivation (Extended Data Fig. 5-1). Here, also, the two mutants displayed gain in apparent affinity for ATP; $\mathrm{EC}_{50}$ s were $45.2 \pm 7.8,7.9 \pm 0.4$, and $4.5 \pm 0.3 \mu \mathrm{M}$ for PG6, PNG6, and PPG6, respectively.

We finally evaluated to what extend these different sensors could detect endogenous ATP release. Hypotonicity is a known stimulus triggering ATP 


\section{Start}

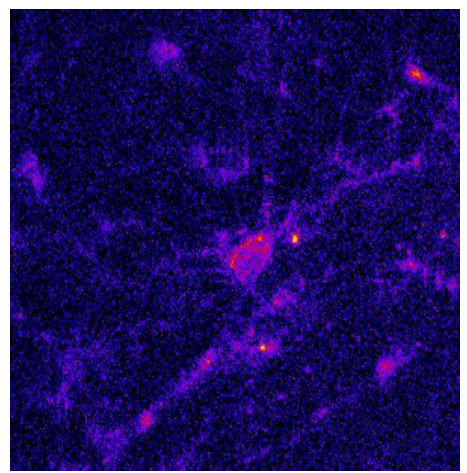

$1 \mu \mathrm{M}$ ATP

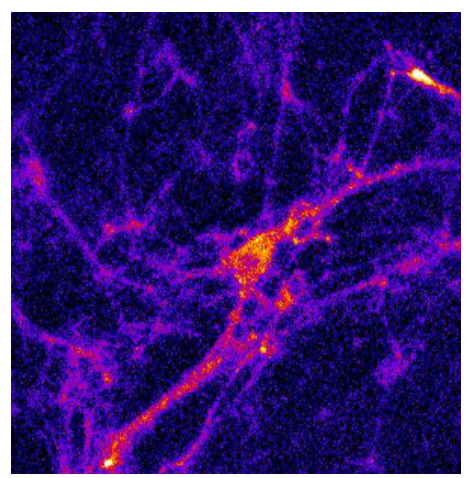

Wash

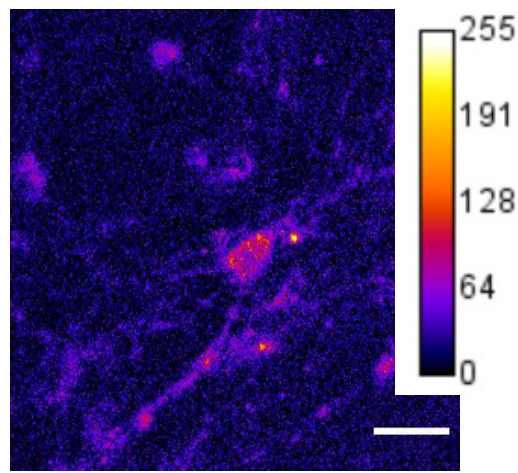

Movie 1. Representative movie of ATP responses in hippocampal neurons expressing PG6, related to Figure 4D. Different ATP concentrations were applied for $10 \mathrm{~s}$ at, at least, 2-min interval. Baseline fluorescence (F0) was calculated by average of the 20 initial frames. Images were pseudo-colored by F/FO ratio and exported as JPEG and played at 31.25 fps. The timer indicates real recording time. Indications of ATP concentration are displayed during 1 min before application (in white) and during the 10-s perfusion (in yellow). Scale bar: $5 \mu \mathrm{m}$. [View online]

release from virtually all cells (Okada et al., 2018). We tested in HEK cells whether ATP release induced by a reduction of extracellular osmolarity could be detected by PNG6 and PPG6 biosensors. A 160 mOsm saline solution ( $50 \%$ reduction of osmolarity) was applied to cells expressing either PG6 or the more sensitive PNG6 biosensors, and fluorescence variations were recorded before a final application of $10 \mu \mathrm{m}$ ATP (Fig. 5F). In cells expressing PNG6 sensor, a biphasic increase of fluorescence was observed. The first transient peak is likely because of ATP release evoked by the mechanical stimulation induced by the solution change. The second phase developed slowly with a maximum reached around $5 \mathrm{~min}$ after the reduction of osmolarity, and then slowly decreased to reach a plateau (Fig. 5F). This second phase likely corresponds to the development of cellular regulatory volume decrease, during which ATP is being released. Maximum of fluorescence represented $75.4 \pm 8.1 \%$ of the signal evoked by a $10 \mu \mathrm{m}$ ATP stimulation (Fig. $5 \mathrm{G}$ ). In the presence of $20 \mathrm{U} / \mathrm{ml}$ apyrase, a soluble ectonucleotidase, hypotonicity-evoked fluorescence variations were strongly inhibited, further supporting a hypotonicity-evoked ATP release (Fig. 5F). In cells expressing PG6 sensor, a similar biphasic fluorescence response was observed, albeit with a much lower intensity, $18.2 \pm 1.8 \%$ of the $10 \mu \mathrm{m}$ ATPevoked response (Fig. 5G). Based on these values, we estimated the maximal ATP concentration reached during a hypotonic environment by extrapolating the maximal fluorescence values measured of cells expressing either PNG6 or PG6 in hypotonic conditions to their respective fitted dose-response curves. In both cases similar estimations were obtained with extracellular ATP concentration of $695 \pm 137$ and $656 \pm 26 \mathrm{~nm}$ for the PNG6 and PG6 sensors, respectively (Fig. 5F-H). When similar experiments were performed using a $25 \%$ reduction of osmolarity ( 240 mOsm), no change in fluorescence was observed in cell expressing PG6 sensor, whereas an $18 \pm 3.8 \%$ increase of fluorescence was detected in cells expressing PNG6 biosensor (Extended Data Fig. 6-1), leading to an estimated ATP concentration of $183 \pm 32 \mathrm{~nm}$ (Fig. $5 H$ ). Essentially identical results were obtained with the PPG6 sensor (Extended Data Fig. 6-1B; Fig. 5H). For comparison, extracellular ATP was quantified every $5 \mathrm{~min}$ in the same condition of reduced osmolarity using luciferase-based ATP quantification kit. A similar slowly developing, bell shaped ATP increase was observed, with a maximum reached $5-10 \mathrm{~min}$ after the start of the osmotic challenge (Extended Data Fig. 6-1C).

Red shifted P2X2 and P2X2-N333A sensors were also generated by fusion of the respective CDNA to either RCaMP2 or jRGECO1a. P2X2-RCaMP2 and P2X2N333A-RCaMP2 show the same pharmacology as previously described for the GCaMP6s version, while to the difference with PKG6, P2X2-K69A-RCaMP2 was not activated by ATP up to $50 \mu \mathrm{M}$ (Fig. 6A). ATP EC ${ }_{50} \mathrm{~S}$ for P2X2-RCaMP2, P2X2-N333A-RCaMP2, and P2X2N333A-jRGECO1a were, respectively, $2.6 \pm 0.4 \mu \mathrm{m}$, $448 \pm 77 \mathrm{~nm}$, and $358 \pm 41 \mathrm{~nm}$ (Fig. 6A,D,F). We next compared fluorescence evoked by ATP for P2X2N333A-RCaMP2 and P2X2-N333A-jRGECO1a. At $1 \mu \mathrm{m}$ ATP, $\mathrm{dF} / \mathrm{F}$ signals were twice larger for P2X2-N333A-jRGECO1a compared with P2X2-N333A-RCaMP2 (dF/F $=0.63 \pm 0.03$ and $0.35 \pm 0.01, n=3$ wells, respectively; Fig. 6B). Similarly, P2X2-N333A fused to either RCaMP2 or jRGECO1a dynamically detected ATP release during hypotonic challenge with fluorescence values equal to $80.3 \pm 3.5 \%$ (RCaMP2) and $70.7 \pm 5 \%$ (jRGECO1a) of the response evoked by $10 \mu \mathrm{M}$ ATP (Fig. 6C). Estimation of the maximal ATP concentration released during the hypotonic challenge, $650 \pm 58$ and $743 \pm 24$ nм $(N=3)$ for P2X2-N333A-RCaMP2 and P2X2-N333AjRGECO1a, respectively (Fig. $6 D, E$ ), are close to those observed with PNG6 and PPG6 sensors. These experiments indicate that red shifted ATP sensors have the same sensitivity and properties as the green versions and support that both green and red versions can be used in combination to track the dynamic of 
A

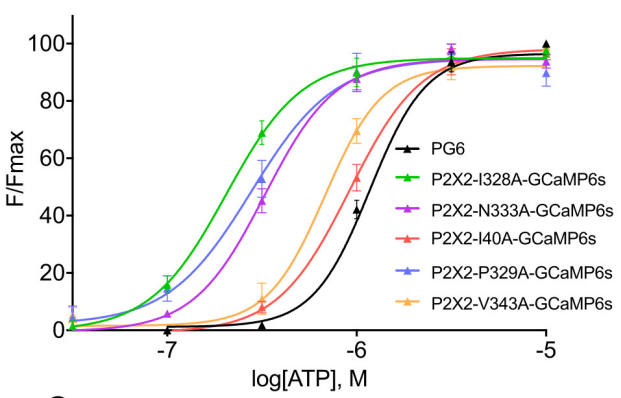

C
B

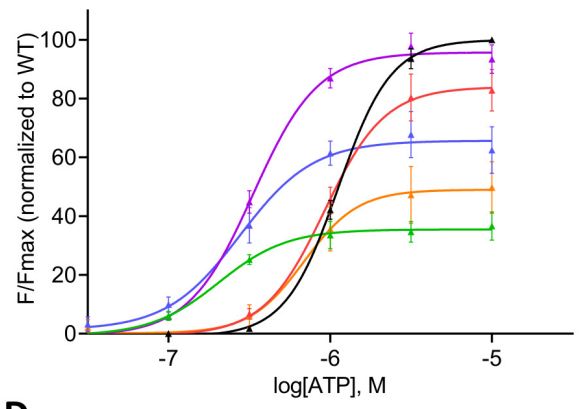

D

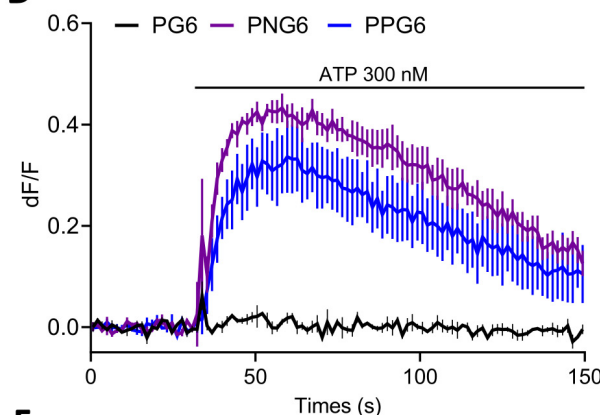

F

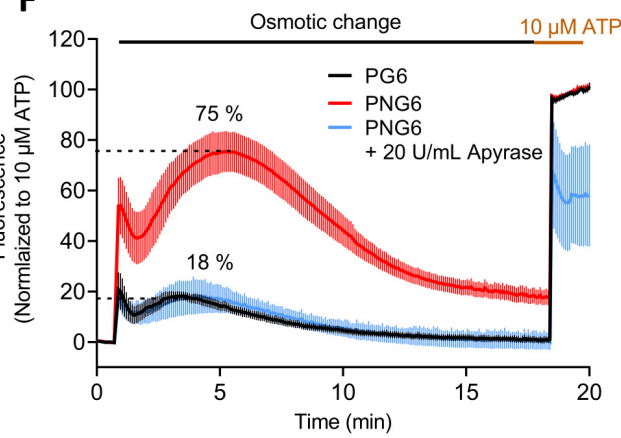

H

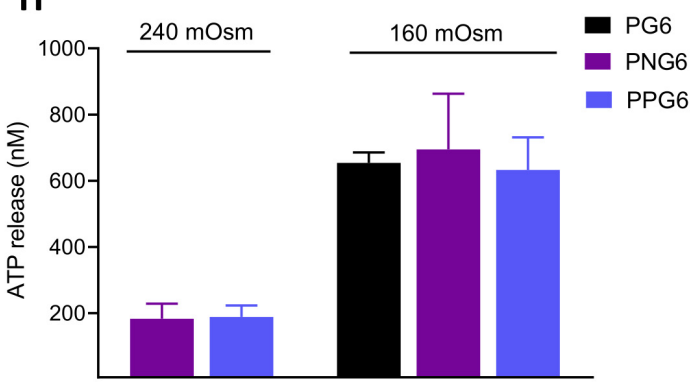

Figure 5. Functional characterization of high sensitivity ATP sensors. A, ATP potency at different single residue mutated PG6. Dose-response curves for ATP were performed in HEK cells transfected with each mutant. Normalized curves were generated from $N=4$ independent experiments. $\boldsymbol{B}$, Dose-response curves for each mutant were normalized to that of PG6, showing that some mutations have significant lower response to saturating dose of ATP. $N=4$ experiments. $\boldsymbol{C}$, Table of the main characteristics for each mutant. $\boldsymbol{D}$, Example traces generated from a plate reader of changes in dF/F values triggered by 300 nм ATP in HEK cells expressing PG6, PNG6 (N333A mutant), and PPG6 (P339A mutant); $n=3$ wells. $\boldsymbol{E}$, Epifluorescence images showing fluorescence changes ( $\lambda$ exc/em 485/540) of HEK cells expressing PG6-P2A-Scarlet, PNG6-P2A-Scarlet, and PPG6-P2A-Scarlet during 300 nM ATP application. Scale bar: $20 \mu \mathrm{m}$. $\boldsymbol{F}$, Sensing ATP release from HEK cell during hypo-osmotic stimulation. Comparison of fluorescence signals recorded in a plate reader from cells expressing PG6 or PNG6 during a 160 mOsm application. Data are normalized to the fluorescence evoked by a $10 \mu \mathrm{M}$ ATP application; $20 \mathrm{U} / \mathrm{ml}$ apyrase strongly inhibited hypotonicity-evoked fluorescence in cells expressing the high sensitive ATP sensor; $n=3$ wells. G, Estimation of the maximal concentration of ATP release during hypotonic challenge. Maximal fluorescent values measured from cells expressing PG6 or PNG6 and reported on their respective dose- 
continued

response fitted curve. $\boldsymbol{H}$, Group data quantification of ATP release during 240 and 160 mOsm hypotonic challenge of cells expressing PG6, PNG6, and PPG6. $N=6$ independent experiments. Data from all panels are mean \pm SEM.

extracellular ATP release in two different cell types within a cellular network.

\section{Discussion}

In this study, we engineered $\mathrm{P} 2 \mathrm{X}$ receptors with the aim i) to directly track their activity and ii) to detect extracellular ATP with fast kinetics and high sensitivity. By fusing the GECI GCaMP6s to the carboxy terminal end of P2X subunits, we generated versatile probes which allow both monitoring $\mathrm{P} 2 \mathrm{X}$ receptor activity and biosensing extracellular ATP release.

The principle of tracking $\mathrm{P} 2 \mathrm{X}$ receptor activity by the mean of a C-terminal fusion with a FRET-based GECl was previously described (Richler et al., 2008). Although this
A

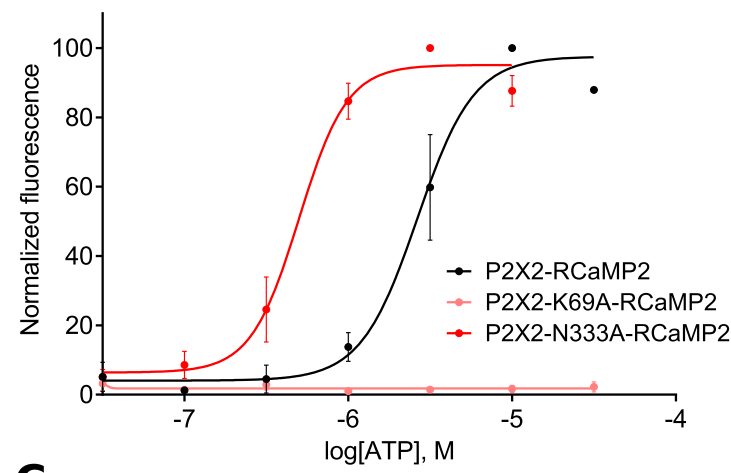

C
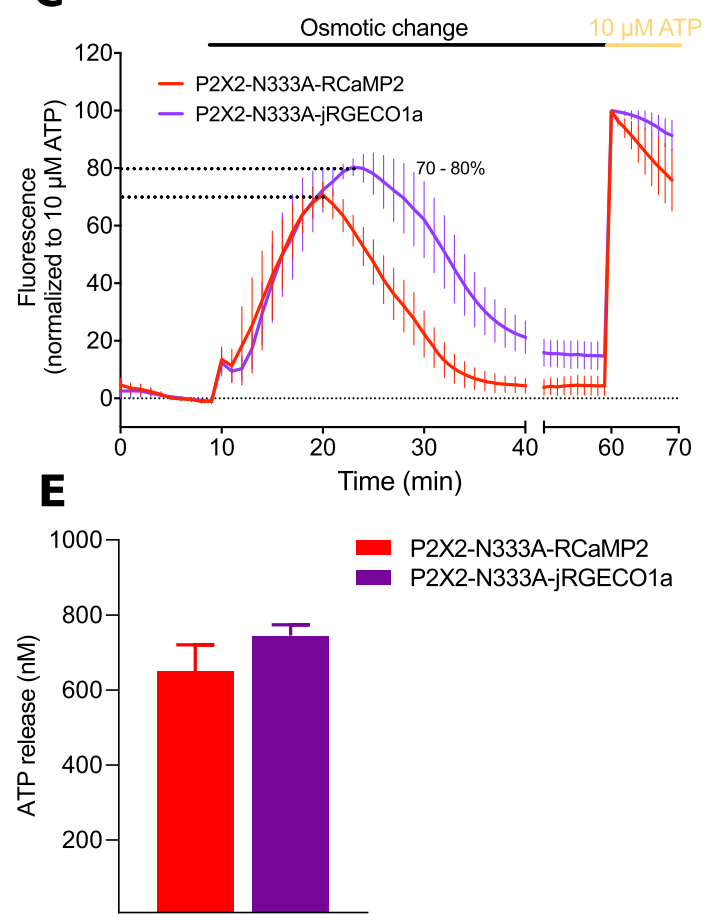

B

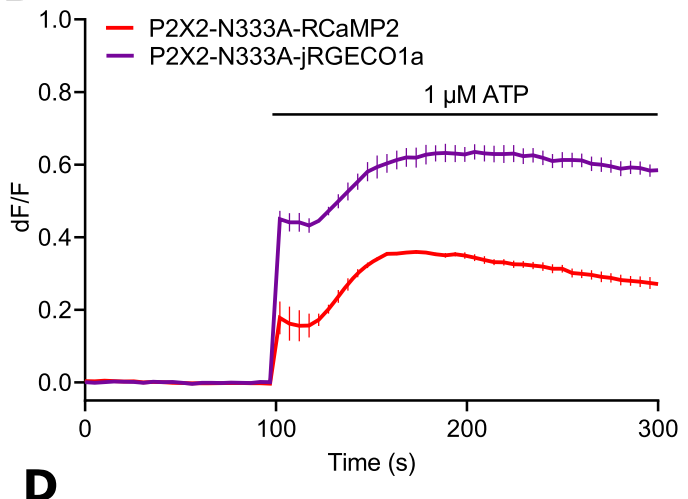

D

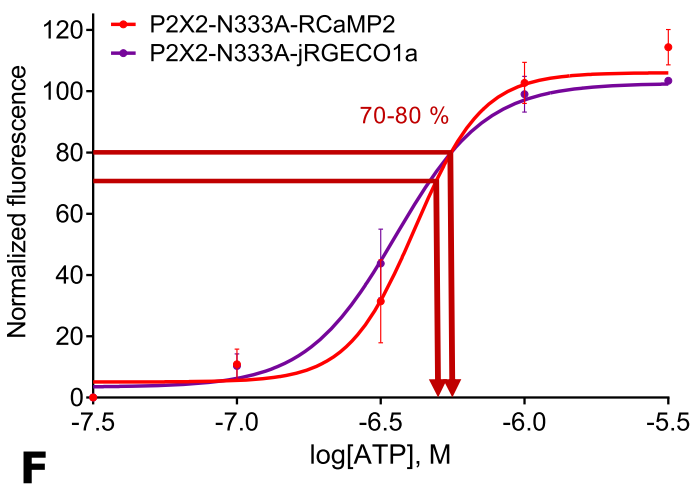

\begin{tabular}{llll} 
Constructs & ATPEC50 $(\mu \mathrm{M})$ & $\mathrm{nH}$ & $\mathrm{dF} / \mathrm{F}$ \\
\hline P2X2-RCaMP2 & $2.6 \pm 0.4$ & $2.5 \pm 1$ & $0.6 \pm 0.1$ \\
\hline P2X2-N333A-RCaMP2 & $0.45 \pm 0.08$ & $3.1 \pm 1.2$ & $0.4 \pm 0.05$ \\
\hline P2X2-N333A-jRGECO1a & $0.36 \pm 0.04$ & $2.8 \pm 1$ & $0.7 \pm 0.1$ \\
\hline
\end{tabular}

Figure 6. Comparison of the red-shifted ATP sensors. A, Pharmacological characterization of P2X2- and P2X2-N333A-RCaMP2. Normalized ATP dose responses curves were performed using a plate reader on HEK cells expressing either P2X2-, P2X2-N333A-, or P2X2-K69A-RCaMP2. B, Representative traces of changes in dF/F values triggered after $1 \mu \mathrm{m}$ ATP application in HEK cells expressing P2X2-N333A-RCaMP2 or P2X2-N333A-jRGECO1a. Note that the jRGECO1a-evoked fluorescence is significantly brighter than RCaMP2. Data were generated from a plate reader with $n>3$ wells per condition. $\boldsymbol{C}$, Comparison of hypotonicity-evoked fluorescence in HEK cells expressing either P2X2-N333A-RCaMP2 or P2X2-N333A-jRGECO1a. Data were normalized to the fluorescence evoked by a $10 \mu \mathrm{M}$ ATP application. $\boldsymbol{D}$, Normalized concentration-response curves for ATP for P2X2-N333A-RCaMP2 or P2X2-N333A-jRGECO1a. Curves were generated from $N=3$ independent experiments. E, Quantification of ATP release during a 160 mOsm hypotonic challenge of cells expressing P2X2-N333A-RCaMP2 and P2X2-N333A-jRGECO1a. N= 4 independent experiments. Data from all panels are mean \pm SEM. $\boldsymbol{F}$, Summary of $\mathrm{EC}_{50}, \mathrm{nH}$, and maximal $\mathrm{dF} / \mathrm{F}$ for $\mathrm{P} 2 \mathrm{X} 2$ red shifted biosensors. 
approach demonstrated its specificity in vitro and in vivo, the use of Cameleon YC3.1 as a fusion partner presented several limitations among which rather slow kinetics and a difficult implementation. We thought that with the improvement of single wavelength $\mathrm{GECl}$ based on circularly permuted fluorescent proteins (GCaMP) most of these limits would be overcome.

Although most of our experiments were based on the P2X2 biosensors, GCaMP6s fusions also report the activity of three additional P2X receptors (P2X4, P2X5, and P2X7) out of the seven possible, which all display ATP potencies, and BzATP in the case of P2X7, in agreement with published values (Jarvis and Khakh, 2009). In our experimental conditions, we were not able to track P2X1 and P2X3 activity as these two receptors desensitize with sub second rates (North and Surprenant, 2000), which is too fast to be detected in our multi well fluorescent plate reader assay. For these subunits, as well for P2X6 that does not form functional receptors, additional experiments using heteromeric receptor expression and/or high-speed drug application combined with high rate of fluorescence acquisition should help to extend our observations to all $\mathrm{P} 2 \mathrm{X}$ subunits.

One potential bias of using GCaMP6s as a reporter of P2X receptor activity might come from fluorescence evoked by intracellular calcium increase unrelated to $P 2 X$ receptor permeability. Our results using P2X2-K69A, a mutant unable to be activated by ATP (Jiang et al., 2000), support that both in HEK cells and neurons, once tethered to P2X2 C terminus, GCaMP6s is almost exclusively activated by calcium influx through $\mathrm{P} 2 \mathrm{X}$ permeation pathway. Although we cannot totally exclude that in some conditions a P2X-independent activation of GCaMP6s might occur, experiments of co-expression of PKG6 with highly calcium permeant channels such as NMDA receptor or TRPV1 clearly indicate that calcium influx through other calcium permeant channels minimally activate PG6. Systematic control experiments using PKG6 should allow to estimate potential contamination of the P2XGCaMP6s signal. Alternatively, assuming that local intracellular calcium concentration is the highest at the vicinity of the inner mouth of the P2X permeation pathway, using GCaMPs in which point mutations are introduced in EF hand and RS20 peptide to lower the affinity for calcium (Helassa et al., 2016) should reduce nonspecific activation of PG6. Such a strategy was successfully used in the case of GenEPi, a Piezo1-based fluorescent reporter for visualizing mechanical stimuli (Yaganoglu et al., 2019). Alternatively, the use of RCaMP2 as a fusion partner could help to reduce non-specific activation of the sensor since in HEK cells, even ATP concentration above $30 \mu \mathrm{m}$ did not evoke activation of K69A-mutated P2X2 red sensor. The reason for the higher specificity of the RCaMP2 sensor is unclear since affinity for calcium is higher for RCaMP2 compared with GCaMP6 (Inoue et al., 2015).

A clear difference in ATP potency on PG6 was observed whether $\mathrm{EC}_{50} \mathrm{~S}$ were measured by whole-cell recording or by acquisition of GCaMP6s fluorescence. Such a difference was not previously reported for the P2X2-Cameleon.
However, the affinities of calcium sensing modules and the conformational changes required to generate fluorescence of GCaMP6s and Cameleon present clear differences (Miyawaki et al., 1999; Chen et al., 2013). It is thus possible that GCaMP6s can report with more accuracy discrete channel opening than Cameleon. In our case, electrophysiological and fluorescence measurements were performed in two HEK cell lines maintained in different laboratory and at two different temperatures (room temperature for electrophysiological recording and $37^{\circ} \mathrm{C}$ for plate reader experiments), which can account for the observed differences in $\mathrm{EC}_{50} \mathrm{~S}$. We also noticed that ATP potency varies as a function of the cell type in which P2X-GCaMP6s are expressed. This is particularly true in neurons where ATP potency at PG6 is one order of magnitude lower to what is observed in HEK cells. These differences in potency might be because of the lipid composition of the plasma membrane, e.g., in cholesterol, which is known to modulate certain P2X receptors (Murrell-Lagnado, 2017). Alternatively, neuronal proteins associated with P2X2 might also modulate apparent affinity of the channel for ATP (Chaumont et al., 2008).

When expressed in neurons, PG6 is localized at the plasma membrane and distributed in the dendritic tree. Purification of synaptoneurosome fractions also supports its enrichment at synapses. Although we did not precisely determine a postsynaptic versus presynaptic localization of PG6, the dendritic expression strongly suggests a postsynaptic localization of the protein. This is in agreement with previous studies showing that in neurons P2X2 traffics to dendrites and to the postsynaptic element where it likely modulates glutamatergic transmission (Richler et al., 2011; Pougnet et al., 2014; Emerit et al., 2016).

In neurons expressing PG6, $\mathrm{KCl}$-evoked neuronal depolarization leads to a fluorescent signal, which likely results from ATP released by neurons. Yet $\mathrm{KCl}$-evoked depolarization did not trigger PKG6 fluorescence, supporting that calcium-entry through voltage-gated calcium channels minimally contributes to activation of GCaMP6s tethered to P2X2 receptor. However, we cannot exclude that ATP evoked activation of PG6 could contribute, to some extent, to neuronal depolarization leading to unspecific GCaMP6 fluorescence.

Activity associated to PG6 sensor is certainly the main limitation of this sensor, which can somehow affect cell physiology either by contributing to direct or indirect calcium influx. Our experiments using c-Fos as a readout of activity-dependency indicate that, in resting conditions (i.e., without exogenous ATP application) viral expression of PG6 does not trigger c-Fos expression. In addition, on BDNF application the number of c-Fos positive neurons was not different between transduced and un-transduced neurons. In brain, extracellular ATP concentrations are thought to be below $10 \mathrm{~nm}$ (Beamer et al., 2019), well below PG6 $\mathrm{EC}_{50}$; in addition, ATP is metabolized within seconds by ectoATPases (Picher et al., 2004). It seems thus unlikely that, in resting conditions, PG6 expression in neurons might be activated by endogenously released 
ATP and thus perturb intracellular calcium homeostasis. Altogether, these results suggest that the PG6 biosensors are capable of detecting endogenous ATP dynamics without perturbing significantly cell physiology. Future experiments will be necessary to further demonstrate that PG6 biosensor can efficiently detect ATP release in response to neuronal activity ex vivo and eventually in vivo.

Because extracellular ATP concentrations are usually low (Beigi et al., 1999; Gourine et al., 2005), sensitivity of ATP sensors is an important parameter. The introduction of point mutation in P2X2 (e.g., N333A, P329A) known to improve the potency of the receptor for ATP (Li et al., 2004), leads to the generation of a series of extracellular ATP biosensors with a sensitivity covering a 100-1000 nM range. These sensors dynamically detected ATP release induced by a $25 \%$ reduction of extracellular osmolarity, which we estimated below $200 \mathrm{~nm}$. Altogether, these data provide proof of concept that PG6 could be instrumental to dynamically detect events of ATP release in diverse cellular contexts.

Different optical, genetically engineered, extracellular ATP biosensors have been generated, which all display different specificities on four main parameters, i.e., sensitivity, kinetics, brightness, and dynamic range (Wu and $\mathrm{Li}, 2020$ ). Although we did not perform in depth characterization of these parameters, P2X-GCaMP6s sensors characteristics outperform that of most other optical biosensors. First, P2X-GCaMP6s sensors offer a large range of sensitivity from nanomolar range (PNG6) up to millimolar range (P2X7-GCaMP6s). Second, activation kinetics of PG6 are very fast $(<600 \mathrm{~ms}$ at $1 \mu \mathrm{m}$, and $<250 \mathrm{~ms}$ at $10 \mu \mathrm{M}$ ). This is not surprising since both P2X2 and GCaMP6s activates within millisecond time scale (Markwardt, 2007; Chen et al., 2013). Off rate kinetics of PG6 fluorescence are slower, yet this parameter is constrained by the inactivation kinetics of GCaMP6s which is in the range of several seconds. However, these characteristics of PG6 can be further improved through the use of ultrafast version of GCaMP6 (Helassa et al., 2016). Nevertheless, PG6 is likely to present the fastest kinetics among the all-existing optical ATP biosensors. Finally, owing to the dynamic range performance of GCaMP6 series, P2XGCaMP6s sensors present very good dF/F0, greater than one for most constructs expressed in HEK cells.

Finally, we also generated red-shifted variants of P2Xbased ATP sensors. Particularly, P2X2-jRGECO1a series present a dF/F close to that of PG6. Two-colors ATP sensors should allow to get a better understanding of the ATP signaling dynamic, particularly in the brain where paracrine action of ATP is thought to contribute to network activities in both physiological and pathologic conditions. Altogether, performances of P2X-GCaMP6s series should allow to dynamically detect extracellular ATP release events with high sensitivity and rapid kinetics, although the activity of $\mathrm{P} 2 \mathrm{X}$ receptors might represent a limitation to its use in specific conditions. These sensors should therefore represent powerful tools to investigate mechanisms of ATP release and signaling as well as to track P2X receptor activity in situ.

\section{References}

Beamer E, Conte G, Engel T (2019) ATP release during seizures - a critical evaluation of the evidence. Brain Res Bull 151:65-73.

Beigi R, Kobatake E, Aizawa M, Dubyak GR (1999) Detection of local ATP release from activated platelets using cell surface-attached firefly luciferase. Am J Physiol 276:C267-C279.

Bindels DS, Haarbosch L, van Weeren L, Postma M, Wiese KE, Mastop M, Aumonier S, Gotthard G, Royant A, Hink MA, Gadella TWJ (2017) mScarlet: a bright monomeric red fluorescent protein for cellular imaging. Nat Methods 14:53-56.

Bobanovic LK, Royle SJ, Murrell-Lagnado RD (2002) P2X receptor trafficking in neurons is subunit specific. J Neurosci 22:418144824.

Burnstock G (2006) Pathophysiology and therapeutic potential of purinergic signaling. Pharmacol Rev 58:58-86.

Burnstock G (2018) Purine and purinergic receptors. Brain Neurosci Adv 2:2398212818817494.

Chaumont S, Compan V, Toulme E, Richler E, Housley GDGD, Rassendren F, Khakh BSBS (2008) Regulation of P2X2 receptors by the neuronal calcium sensor VILIP1. Sci Signal 1:ra8.

Chen TW, Wardill TJ, Sun Y, Pulver SR, Renninger SL, Baohan A, Schreiter ER, Kerr RA, Orger MB, Jayaraman V, Looger LL, Svoboda K, Kim DS (2013) Ultrasensitive fluorescent proteins for imaging neuronal activity. Nature 499:295-300.

Compan V, Ulmann L, Stelmashenko O, Chemin J, Chaumont S, Rassendren F (2012) P2X2 and P2X5 subunits define a new heteromeric receptor with P2X7-like properties. J Neurosci 32:42844296.

Conley JM, Radhakrishnan S, Valentino SA, Tantama M (2017) Imaging extracellular ATP with a genetically-encoded, ratiometric fluorescent sensor. PLoS One 12:e0187481.

Deaglio S, Robson SC (2011) 301-332. Ectonucleotidases as regulators of purinergic signaling in thrombosis, inflammation, and immunity. Adv Pharmacol 61:301-332.

Emerit MB, Baranowski C, Diaz J, Martinez A, Areias J, Alterio J, Masson J, Boué-Grabot E, Darmon M (2016) A new mechanism of receptor targeting by interaction between two classes of ligandgated ion channels. J Neurosci 36:1456-1470.

Gourine AV, Llaudet E, Dale N, Spyer KM (2005) ATP is a mediator of chemosensory transduction in the central nervous system. Nature 436:108-111.

Helassa N, Podor B, Fine A, Török K (2016) Design and mechanistic insight into ultrafast calcium indicators for monitoring intracellular calcium dynamics. Sci Rep 6:38276.

Hou Z, Cao J (2016) Comparative study of the P2X gene family in animals and plants. Purinergic Signal 12:269-281.

Inoue M, Takeuchi A, Horigane S, Ohkura M, Gengyo-Ando K, Fujii H, Kamijo S, Takemoto-Kimura S, Kano M, Nakai J, Kitamura K, Bito $H$ (2015) Rational design of a high-affinity, fast, red calcium indicator R-CaMP2. Nat Methods 12:64-70.

Jacobson KA, Müller CE (2016) Medicinal chemistry of adenosine, P2Y and P2X receptors. Neuropharmacology 104:31-49.

Jarvis MF, Khakh BS (2009) ATP-gated P2X cation-channels. Neuropharmacology 56:208-215.

Jiang LH, Rassendren F, Surprenant A, North RA (2000) Identification of amino acid residues contributing to the ATP-binding site of a purinergic P2X receptor. J Biol Chem 275:3419034196.

Kawate T, Michel JC, Birdsong WT, Gouaux E (2009) Crystal structure of the ATP-gated P2X(4) ion channel in the closed state. Nature 460:592-598.

Khakh BS, Alan North R (2006) P2X receptors as cell-surface ATP sensors in health and disease. Nature 442:527-532.

Kukulski F, Lévesque SA, Sévigny J (2011) Impact of ectoenzymes on P2 and P1 receptor signaling. Adv Pharmacol 61:263-299.

Lazarowski E (2008) Regulated release of nucleotides and UDP sugars from astrocytoma Cells. Novartis Found Symp 276:73-90. 
Lazarowski ER, Sesma JI, Seminario-Vidal L, Kreda SM (2011) Molecular mechanisms of purine and pyrimidine nucleotide release. Adv Pharmacol 61:221-261.

Li Z, Migita K, Samways DSK, Voigt MM, Egan TM (2004) Gain and loss of channel function by alanine substitutions in the transmembrane segments of the rat ATP-gated P2X2 receptor. J Neurosci 24:7378-7386.

Llaudet E, Hatz S, Droniou M, Dale N (2005) Microelectrode biosensor for real-time measurement of ATP in biological tissue. Anal Chem 77:3267-3273.

Lobas MA, Tao R, Nagai J, Kronschläger MT, Borden PM, Marvin JS, Looger LL, Khakh BS (2019) A genetically encoded single-wavelength sensor for imaging cytosolic and cell surface ATP. Nat Commun 10:711.

Lohman AW, Billaud M, Isakson BE (2012) Mechanisms of ATP release and signalling in the blood vessel wall. Cardiovasc Res 95:269-280.

Markwardt F (2007) Activation kinetics of single P2X receptors. Purinergic Signal 3:249-253.

Miyawaki A, Griesbeck O, Heim R, Tsien RY (1999) Dynamic and quantitative $\mathrm{Ca} 2+$ measurements using improved cameleons. Proc Natl Acad Sci USA 96:2135-2140.

Moutin E, Hemonnot AL, Seube V, Linck N, Rassendren F, Perroy J, Compan V (2020) Procedures for Culturing and Genetically Manipulating Murine Hippocampal Postnatal Neurons. Front Synaptic Neurosci 12:19.

Murrell-Lagnado RD (2017) Regulation of P2X Purinergic Receptor Signaling by Cholesterol. Curr Top Membr 80:211-232.

North RA, Surprenant A (2000) Pharmacology of cloned P2X receptors. Annu Rev Pharmacol Toxicol 40:563-580.

Okada Y, Okada T, Islam MR, Sabirov RZ (2018) Molecular identities and ATP release activities of two types of volume-regulatory anion channels, VSOR and Maxi-Cl. Curr Top Membr 81:125-176.

Pellegatti P, Falzoni S, Pinton P, Rizzuto R, Di Virgilio F (2005) A novel recombinant plasma membrane-targeted luciferase reveals a new pathway for ATP secretion. Mol Biol Cell 16:3659-3665.
Picher M, Burch LH, Boucher RC (2004) Metabolism of P2 receptor agonists in human airways: implications for mucociliary clearance and cystic fibrosis. J Biol Chem 279:20234-20241.

Pougnet J-T, Toulme E, Martinez A, Choquet D, Hosy E, BouéGrabot E (2014) ATP P2X receptors downregulate AMPA receptor trafficking and postsynaptic efficacy in hippocampal neurons. Neuron 83:417-430.

Praetorius HA, Leipziger J (2009) ATP release from non-excitable cells. Purinergic Signal 5:433-446.

Rassendren FF, Audinat E (2016) Purinergic signaling in epilepsy. J Neurosci Res 94:781-793.

Richler E, Chaumont S, Shigetomi E, Sagasti A, Khakh BS (2008) Tracking transmitter-gated $\mathrm{P} 2 \mathrm{X}$ cation channel activation in vitro and in vivo. Nat Methods 5:87-93.

Richler E, Shigetomi E, Khakh BS (2011) Neuronal P2X2 receptors are mobile ATP sensors that explore the plasma membrane when activated. J Neurosci 31:16716-16730.

Sivaramakrishnan V, Bidula S, Campwala H, Katikaneni D, Fountain SJ (2012) Constitutive lysosome exocytosis releases ATP and engages P2Y receptors in human monocytes. J Cell Sci 125:45674575.

von Kügelgen I (2019) Pharmacology of P2Y receptors. Brain Res Bull 151:12-24.

von Kügelgen I, Harden TK (2011) Molecular pharmacology, physiology, and structure of the P2Y receptors. Adv Pharmacol 61:373415.

Weisman GA, Woods LT, Erb L, Seye C (2012) P2Y receptors in the mammalian nervous system: pharmacology, ligands and therapeutic potential. CNS Neurol Disord Drug Targets 11:722-738.

Wu Z, Li Y (2020) New frontiers in probing the dynamics of purinergic transmitters in vivo. Neurosci Res 152:35-43.

Yaganoglu S, Helassa N, Gaub BM, Welling M, Shi J, Müller DJ, Török K, Pantazis P (2019) GenEPi: piezo1-based fluorescent reporter for visualizing mechanical stimuli with high spatiotemporal resolution. bioRxiv. doi: https://doi.org/10.1101/702423. 